\title{
UNA NUEVA EVALUACION \\ MACROECONOMICA \\ DE LA REVOLUCION INDUSTRIAL *
}

\author{
C. Knick Harley \\ Universidad de Western Ontario
}

\begin{abstract}
SUMARIO
El crecimiento económico durante la Revolución Induetrial ha sido sometido en in última década a una nueva evaluación que reviea anteriones teories sobre el deanrrollo britínico. El crecimiento fue mis lento, y el cambio induatrial eatuvo mis localizado y produjo un menor impacto de lo que se pensaba anteriormente. Las mejoras en la agricultura y la relativa facilidad con que la mano de obra se pasó a in industria urbana parecen centrales en eata experiencia. Aunque el impacto industrial ahora aparece menor de lo que antes se crein, les ciudades induatriales transformanon la sociedad porque la industria algodonera se expandió para aprovechar la ventaja que le daba au nueva tecnologia, y los trabajadores se trasladaron a las ciudades. Pero, aunque las exportaciones aumentaron la participación de la inductria y dieron lugar a la urbaniza. ción, no elevaron mucho la renta por habitante porque la competencia consiguió que los beneficios fueran para los consumidores. Por ültima, parece que los rasgos especificos de la revolución industrial británica no constítuyen una guía muy eólida para el proceso del crecimiento en otros lugares.
\end{abstract}

\section{ABSTRACT}

Apgregate extimates of Britiah growth during the classical Industrial Revolution have been reasesesed in the past decade and present a significantly revision of earlier views of Britiah growth. Growth was alower then previously believed and industrial

* En la sesión C, «New Ways to Think About the Industrial Revolution*, del X Congreso Internacional de Historia Económica celebrado en Lovaina, en agosto de 1990, se presentó una versión anterior del presente trabajo. Me he beneficiado de los comentarios que alli se hicieron así como de los participantes en seminarios de las universidades de Western Ontario, Indiana, Nova de Lisboa y Carlos III de Madrid. Agradezco especialmente los comentarios de Joel Mokyr y Nathan Sussman. 
change more localized and with a smaller impact. Agricultural improvement and the relative ease with which labour moved to urban industry seems central to the experience. Although industry's impact now seems less than previously believed, induetrial cities transformed society because the cotton textile industry expanded to exploit the advantage of its new technology and labour moved to the cities. But while exports expanded the share of industry and caused urbanization, they did not raise per capita income much because competition enoured that the benefits went to consumers. Finally, the specific features of the British industrial revolution seem to provide only weak guide to the growth process elsewhere.

Desde mediados del siglo xix, el nivel de vida ha venido aumentando en Europa occidental y en las regiones del mundo con población europea. La reciente historia demográfica nos da una larga perspectiva del crecimiento europeo ${ }^{1}$. Si se hace una yuxtaposición de la población inglesa y el salario real de los trabajadores en los últimos siete siglos (figura 1), se descubre un cambio espectacular hacia el año 1800 . En los siglos anteriores y durante largos periodos, los salarios reales aumentaban y descendian en relación inversa a la población, pero sin una tendencia secular. La Peste Negra mató en el siglo xIV alrededor de un tercio de la población de Inglaterra, que se mantuvo en niveles bajos hasta principios del siglo xvi. En aquella población, más reducida, los trabajadores disfrutaron de unos salarios que casi duplicaban los de sus antepasados, anteriores a la Peste. La población creció durante el siglo xvi y primera mitad del xvir y los salarios descendieron a los niveles anteriores a la Peste. La historia corroboró las previsiones teóricas de los economistas, desarrolladas primeramente por David Ricardo alrededor de 1800, según las cuales, en una economía constreñida por unos recursos limitados, los salarios varian en razón inversa a la población.

Desde los tiempos de Ricardo, la relación inversa población/salarios ha desaparecido. Entre 1820 y 1980, la población inglesa aumentó desde 11,5 millones hasta más de 45 millones (a un ritmo del 26 por ciento por siglo). En los cinco siglos anteriores, la población aumentaba a un ritmo aproximado del 14 por ciento por siglo, y en general, la tecnologia y el capital iban avanzando lo suficiente como para mantener el nivel de vida. Las estadísticas son imprecisas, pero la imagen general es clara: la relación población/medio-ambiente cambió de forma radical. La transformación de la economia europea es indiscutible, pero su naturaleza permanece poco clara. ¿Fue un proceso rápido o dilatado? ¿Transformó la economía la nueva tecnologia manufacturera? ¿Qué papeles

1 Wrigley y Schofield (1981), Lee (1973, 1988). 
desempeñaron la agricultura y el comercio exterior? La investigación reciente ha reconsiderado estas persistentes preguntas.

\section{CONCEPCIONES DE LA REVOLUCION INDUSTRIAL}

Desde el siglo XIX la mayoria de los observadores pensaron que a finales del siglo XVIII las innovaciones industriales clave transformaron la economía y alteraron rápida y fundamentalmente la sociedad. En 1845 Friedrich Engels comenzaba con las siguientes frases su obra La situación de la clase trabajadora en Inglaterra:

La historia de las clases trabajadoras inglesas comienza en la segunda mitad del siglo xvill con el invento de la máquina de vapor y de las máquinas para la hilatura y el tejido del algodón. Es bien sabido que estos inventos dieron impulso a la revolución industrial. Esta revolución tuvo un aspecto social además de económico, puesto que transformó toda la estructura de la sociedad burguesa.

Los historiadores profesionales expresaron parecidas opiniones. En 1884, Amold Toynbee retrataba a la sociedad como

repentinamente hecho pedazos por los duros golpes de la máquina de vapor y el telar mecánico.

Las siguientes generaciones de historiadores por lo general compartieron esta opinión. En los años de entreguerras, sir John Clapham formuló una teoría gradualista en su extensa historia económica de Gran Bretaña, sin desplazar la predominante visión de clase de la Revolución Industrial.

Tras la Segunda Guerra Mundial, los historiadores trasladaron su interés al desarrollo económico y buscaron un modelo de crecimiento en la industrialización europea. En su obra Las etapas del crecimiento económico ${ }^{2}$ Walt Rostow desarrolló un modelo enfático y popular en el que un dinámico sector dominante y una inversión notablemente incrementada llevaron a un «despegue hacia un crecimiento autosostenido a lo largo de un par de décadas. Gran Bretaña «despegó» entre 1783 y 1802 . Una cronologia tan exacta inevitablemente dio lugar a la polémica. No obstante, gran parte de la historiografia buscó un

\footnotetext{
2 Rostow, Walt, (1960).
} 
periodo breve del que extraer lecciones para la planificación del desarrollo en paises contemporáneos de renta baja ${ }^{3}$.

En los últimos treinta años, los historiadores económicos se han ido apoyando cada vez más en datos cuantitativos y en estimaciones de los agregados económicos clave. Los primeros estudios de los agregados -el índice de producción industrial de Walter Hoffmann y los índices de la renta nacional de Phyllis Deane y Arthur Cole- tuvieron una enorme influencia 4 . En la década de 1950, los historiadores con formación económica (los «nuevos historiadores económicos») comenzaron a influir sobre el modo de escribir la historia económica. Se esforzaron por unir los modelos formales de la economía en su conjunto con la cuantificación. Su búsqueda de datos les condujo a Hoffmann y a Deane y Cole.

El indice de Hoffmann se publicó en Alemania en los años de entreguerras y en inglés en 1955. Aunque recibió considerables críticas, fue ampliamente citado. Deane y Cole (después de rechazar el indice de Hoffmann para el siglo XviI por tener «una base demasiado frágil para ser concluyente») publicaron una estimación independiente del desarrollo industrial como parte de las estimaciones de la renta nacional. Los procedimientos seguidos por Hoffmann y Deane y Cole dieron como resultado unas estimaciones parecidas, que confirmaban la antigua opinión de que en los cincuenta años anteriores a 1830 se produjo un importantisimo cambio estructural en la industria británica. Ambos indices mostraban que el crecimiento de la producción industrial saltó desde menos de un 1 por ciento anual entre 1700 y aproximadamente 1770 , hasta un dos y medio por ciento anual durante el siguiente medio siglo, acelerándose un poco más en las décadas siguientes.

Hasta hace muy poco, las estimaciones de la renta nacional de Deane y Cole fueron el incuestionable telón de fondo de la investigación. La investigación cuantitativa de las industrias individuales reveló que el crecimiento agregado de Deane y Cole no pudo deberse únicamente al famoso cambio tecnológico producido en los textiles, el hierro y el vapor, ni siquiera haciendo una valoración muy libre de sus vinculaciones con el resto de la economia. Entonces surgió una síntesis que fusionaba la apreciación de la economía rebasando los famosos sectores, de Clapham, con las estimaciones cuantitativas de Deane y Cole s. En la década de 1960 Max Hartwell articuló la teoría de que el cambio se dio en un gran abanico de sectores. Una generación más tarde Donald

3 David Canadine (1989) ha realizado un interesante análisis de las teorias sobre la Revolución Industrial durante el siglo pasado.

4 Walther Hoffmann (1955), Phyllis Deane (1962) y Arthur Cole (1962).

s Deane y Cole realizaron los primeros trabajos. [P. Deane y A. Cole (1962)]. 
McCloskey resumía la teoría de que el crecimiento resultó de un avance tecnológico extendido pero desigual, con una metáfora meteorológica 6 :

Los nuevos inventos mecánicos cayeron más bien como una lluvia mansa, aunque sin precedentes, que se juntaba aqui y allá formando charcos. En 1860 el terreno quedó húmedo, pero de ninguna forma empapado, ni siquiera en los puntos más mojados.

Ya en los primeros años de la década de 1980, la investigación y la sintesis, hechas con el espiritu de Hartwell-McCloskey, habian cambiado la impresión general sobre la Revolución Industrial. El estudio de las industrias individuales habia revelado un cambio gradual. Las innovaciones en los textiles, el hierro y la energía no habian podido causar más que un impacto modesto sobre el nivel de vida. La idea de una (..heroica..) Revolución Industrial originada por la iniciativa de unos pocos grandes hombres de empresa había dado paso a una teoria según la cual el cambio tuvo una amplia base dentro del entramado de la sociedad británica.

En la última década, una nueva valoración del crecimiento agregado ha cambiado una vez más la idea que se tenía de la Revolución Industrial. Las fuertes subidas de la producción industrial y del crecimiento de la renta durante el último cuarto del siglo xvm aparecen como resultados de una errónea construcción de los índices de Hoffmann y Deane y Cole. Ahora se descubre que en la manufactura el cambio se concentró mayoritariamente en las famo. sas industrias, que la agricultura tuvo una gran contribución y que el crecimiento se aceleró de forma gradual durante muchas décadas.

\section{LAS NUEVAS ESTIMACIONES AGREGADAS}

Para valorar el desarrollo británico hemos de considerar todo el abanico de las actividades económicas. Incluso en las sociedades industriales modernas, las estadisticas sobre la renta nacional presentan problemas teóricos y empíricos; en un análisis de la Gran Bretaña del siglo xvm los problemas sólo pueden ser conjeturas controladas. No obstante, sin ellas no puede entenderse el desarrollo. Los factores de producción alternaban entre varios usos, y algunos sectores hubieran podido crecer incluso en una economia estática. Es necesaria la agregación para encontrar el equilibrio entre los sectores en crecimiento y aquellos en declive.

\footnotetext{
- Donald McCloskey (1981), p. 106.
} 
Una estimación ideal de la renta nacional es la que comprende una enumeración completa de la vida económica. Las rentas de los factores productivos, los valores añadidos en los diversos sectores y el valor de las ventas finales contribuyen cada uno a la renta nacional. Las burocracias estadísticas modernas reúnen todos estos datos para construir las estadisticas de la renta nacional. Pero para calcular la renta nacional anterior a los comienzos de la contabilidad nacional, se requiere, sin embargo, un uso creativo de los censos de población y de los ingresos fiscales y otros datos cuantitativos disponibles. A principios de la década de 1960, Phyllis Deane y Arthur Cole completaron un amplisimo programa de investigación que proporcionó estimaciones de la renta nacional histórica en Gran Bretaña. Estas estimaciones siguen siendo los cimientos sobre los cuales todos los demás han construido. Pero en la última década, N. F. R. Crafts (1985) ha criticado eficazmente las estimaciones de Deane y Cole y ha aportado estimaciones de la renta nacional muy diferentes. $\mathrm{Mu}$ chos detalles del trabajo de Crafts eran especulativos y algunos de sus aspectos están envueltos en controversia, pero en general sus conclusiones han desplazado sustancialmente a las de Deane y Cole?

Las estimaciones de la renta nacional británica anterior a la segunda mitad del siglo $\mathrm{xIX}$ requieren una proyección retrospectiva hacia periodos que tienen cada vez menos datos fiables. La enumeración completa de la vida británica se inició en 1801 con los primeros censos decenales de población. Los primeros censos fueron ejercicios exploratorios y de poca calidad según las pautas modernas, pero gradualmente la enumeración se fue haciendo más fidedigna. Mediado el siglo los censos contenian ya una útil información ocupacional. El censo de 1841, aunque considerado algo incompleto, contiene los primeros datos acreditados sobre la fuerza laboral que permiten construir estimaciones de la renta del trabajo ${ }^{8}$. El impuesto sobre la renta durante las Guerras Napoleónicas y tras su reimposición en 1842 proporcionaron información sobre la renta patrimonial 9 . Utilizando estas fuentes, Deane y Cole estimaron las rentas de los factores productivos y la renta nacional de 1801 en adelante. La evidencia disponible era débil antes de 1841 , pero mejoró a partir de ese año. En la década de 1880 los funcionarios comenzaron a reunir datos globales sobre la producción agricola, y el primer censo de la producción industrial se realizó en 1907.

T Inevitablemente, el nuevo trabajo de Craft atrajo críticas. Vėase Mokyr (1987), Williamson (1987), Hoppit (1990), Jackson (1990), Berg y Hudson (1992). Para un comentario sobre estas criticas, véase Crafts y Harley (1992).

- P. Deane y A. Cole (1962), pp. 139-140.

T P. Deane y A. Cole (1962), pp. 164 y ss. 
Antes del siglo xIX algunos comentaristas políticos intentaron calcular la renta nacional partiendo de los datos a que tenían acceso ${ }^{10}$, pero las estimaciones de la renta nacional anteriores a la década de 1840 consistieron sobre todo en proyecciones retrospectivas. Se utilizaron cifras de población (según los censos y estimadas anteriormente), series de producción incompletas, e inferencias diversas, para intentar proyectar hacia fechas más tempranas, desde la relativa certeza de mediados del siglo $\mathrm{XIX}$.

Hasta hace muy poco, ni siquiera la población británica anterior a 1801 - uno de los principales elementos para las primeras estimaciones de la renta nacional - ha sido bien conocida. Afortunadamente, una amplia investigación sobre dos décadas, dirigida por E. A. Wrigley y R. Schofield, ha mejorado mucho la cuestión en ese aspecto ${ }^{11}$. Incluso aquí los historiadores han tenido que apoyarse en estimaciones construidas sobre datos parciales, pero la mayoría piensa hoy que las estimaciones indican con exactitud la corriente de la población en el siglo xvin.

\section{La praducción industrial}

La interpretación tradicional presenta a la tecnologia industrial como iniciadora del desarrollo moderno a finales del siglo xvin. El algodón y después otros textiles se transformaron, Watt perfeccionó radicalmente la máquina de vapor y diversos avances condujeron a la fundición del hierro con coque. ¿Hasta qué punto estas mejoras condujeron a un aumento de la producción industrial en su conjunto y de la renta nacional?

\section{Datos}

Los datos básicos sobre la producción industrial proceden de diversas fuentes y presentan algunos problemas de fiabilidad. El Estado británico se hallaba alejado de casi toda la actividad económica y carecía del aparato estadístico de un Estado moderno. La mayoría de los datos globales que existen tienen su origen en los ingresos obtenidos por el Estado por derechos arancelarios sobre los bienes comerciados internacionalmente y por impuestos indirectos sobre el consumo nacional. Pero grandes sectores de la manufactura

10 P. Deane (1955), Lindert y Williamson (1982) (1983a).

11 E. A Wrigley y R. Schofield (1981). 
eludieron la atención fiscal del Estado y aqui los registros fiscales proporcionan poca información. Afortunadamente los historiadores han estudiado las más importantes entre estas industrias y han construido estimaciones de su crecimiento. Pero, aun asi, contamos con escasa información sobre una parte considerable de la manufactura. Los datos básicos son claramente imperfectos y deben utilizarse con cautela ${ }^{12}$.

Los textiles y la confección constituían casi la mitad de la manufactura total en la Gran Bretaña de mediados del siglo xvil. Podemos seguir el proceso de crecimiento de la nueva industria textil del algodón con una cierta confianza, ya que todo el algodón en rama era importado. Los textiles antiguos inicialmente más importantes, que empleaban materias primas nacionales - lana y lino-, han dejado desgraciadamente cifras mucho menos precisas. Phyllis Deane ${ }^{13}$ hizo una valoración detallada de los datos imperfectos sobre la lana, y Deane y Cole realizaron estimaciones sobre el lino y la seda ${ }^{14}$. Las tendencias de la industria de la confección pueden calcularse a partir de los textiles retenidos para el consumo interno.

El hierro y el carbón no tributaban, pero los historiadores han realizado estimaciones de su producción 15. Las estimaciones de la producción de hierro, más sus importaciones, pueden utilizarse para indicar la tendencia de la producción de las industrias transformadoras de metales ${ }^{16}$. Los registros de los impuestos indirectos revelan la historia de algunos otros sectores. Los curtidos, un gran sector manufacturero preindustrial, tributaban. $Y$ también las industrias papeleras y tipográficas y la producción de cerveza ${ }^{17}$. La producción de las industrias alimentarias puede inferirse a partir de la producción agricola. Las estimaciones sobre la formación de capital han servido de base para estimar el nivel de actividad en la industria de la construcción ${ }^{18}$. Pero no hay casi ninguna indicación sobre las tendencias de crecimiento de aproximadamente el 10 por ciento de la actividad industrial; aquí probablemente la producción siguió el ritmo del crecimiento de la población.

El cuadro 1 presenta los indices, por otra parte, bastante imprecisos, de producción para algunas industrias en 1815 y 1770 (tomando como 100 el ni(1992).

12 Hoppit (1990), pero también Mitchell y Deane (1962), pp. 242-244, y Crafts y Harley

13 P. Deane (1957), Holderness (1989), pp. 171-174.

14 P. Deane y A. Cole (1962), pp. 202-211.

15 Hyde (1977), pp. 204-206, y Pollard (1980).

16 Harley (1982), pp. 273-275.

17 Mitchell y Deane (1962), pp. 247-267; Hoffmann (1955), Pp. 291-330, y Deane y Cole (1962), pp. 50-62.

18 Feinstein (1978), p. 40; 1988a, p. 446. 


\section{CUADRO 1}

Indices de output, diversas industrias (1841 - 100)

\begin{tabular}{|c|c|c|}
\hline Industria & 1770 & 1815 \\
\hline 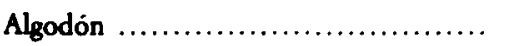 & 0,8 & 19 \\
\hline 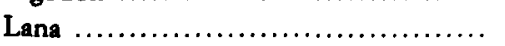 & 46 & 65 \\
\hline 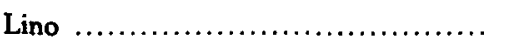 & 47 & 75 \\
\hline Seda $\ldots \ldots \ldots \ldots \ldots \ldots \ldots \ldots \ldots \ldots \ldots$ & 28 & 40 \\
\hline 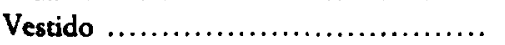 & 20 & 43 \\
\hline 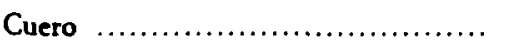 & 41 & 61 \\
\hline Metal $\ldots \ldots \ldots \ldots \ldots \ldots \ldots \ldots \ldots \ldots \ldots$ & 7 & 29 \\
\hline Alimentación $\ldots \ldots \ldots \ldots \ldots \ldots \ldots \ldots$ & 47 & 69 \\
\hline Papel e impresión ....................... & 17 & 47 \\
\hline 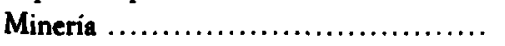 & 15 & 46 \\
\hline 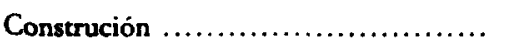 & 26 & so \\
\hline 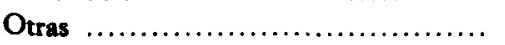 & 15.20 & $40 \cdot 60$ \\
\hline
\end{tabular}

FUENTE: Harley (1982), p. 273, con una modificación en la construcción para reflejar nuevas estimaciones del atotal de edificios y construcciones», de Feinstein (1988), p. 446.

vel de producto en 1841). Resalta el muy rápido crecimiento de los textiles de algodón; en 1770 su producción era sólo el 0,8 por ciento de la que alcanzó en 1841. Por el contrario, otras industrias crecieron lentamente. La producción metalúrgica, segunda industria en ritmo de crecimiento, tenía en 1770 casi el 7 por ciento de su nivel en 1841; en otros grandes sectores industriales - los demás textiles, el cuero y la alimentación - alcanzaban ya en 1770 casi la mitad de su producción en 1841 .

\section{La ponderación}

Puesto que los distintos sectores de la industria manufacturera crecieron a ritmos muy diferentes, los índices de producción agregada variarán si se utilizan diferentes ponderaciones. En concreto, si los tejidos de algodón, de rápido crecimiento, reciben un peso grande, la estimación de la producción industrial agregada crecerá mucho más deprisa que si tienen un peso reducido. Es sabido, sin embargo, que una agregación bien hecha requiere sumar las cantidades de diversos bienes valorados a su precio en un determinado año base. Un paso clave en la construcción del índice es la identificación de los precios y las can- 
tidades apropiadas para diversos años base. Durante la Revolución Industrial los precios relativos variaron muy deprisa, sobre todo cuando los avances tecnológicos hicieron bajar los precios de los textiles de algodón. Por lo tanto, unas fechas base diferentes darán como resultado índices diferentes pero igualmente legitimos ${ }^{19}$.

En la práctica los indices de productos suelen elaborarse como un promedio ponderado de la producción en las distintas industrias. Los pesos adecuados son los porcentajes de las diversas industrias en la producción, o, en el valor añadido, en el año base. Este procedimiento equivale a agregar los diferentes subindices con precios del año base. La mayor dificultad para construir un índice de la producción industrial británica anterior a la década de 1840 está en cuantificar la estructura del sector industrial en el año base a fin de disponer de las ponderaciones pesos apropiadas para la agregación. La base ideal resultaría de una enumeración global de los productos e insumos de todas las industrias en un censo de producción industrial. Pero hasta 1907 no se realizó un tal censo. Careciendo de un censo industrial, tenemos que buscar una solución de compromiso.

La clasificación ocupacional del censo de población de 1841 nos proporciona el sucedáneo global más temprano de un censo de la producción industrial 20. Decidí utilizar esta evidencia como indicador de una información ideal aunque inexistente acerca del valor añadido en cada una de las industrias. Distribui las ponderaciones para 1841 en proporción con la mano de obra de ese año en cada industria (dando a las mujeres, los niños y a los tejedores manuales de algodón la mitad del peso que a los varones adultos). Calculé las distribuciones del valor añadido por industrias para las fechas anteriores proyectando retrospectivamente las proporciones del empleo por sectores sirviéndome de los indices de producción industrial, y reajustándolas para conformarlas a

19 En 1841 los algodones eran sólo una tercera parte más caros que en 1770 en relación con los demás productos manufacturados, y sólo la mitad más caros que en 1815. Utilizando los precios de 1770 (un indice de Laspeyres), la agregación valorari más el amplio sector textil del algodón de 1941 que utilizando los precios de 1841 (un indice de Paasche) y conducira a una estimación de crecimiento más rápido. Esta discrepancia es un problema inevitable que tiene el sistern de números indices. Una solución de compromiso entre los pesos iniciales y terminales, que goza de un atractivo y apoyo intuitivo en la teoria del consumo formal, conduce a los indices Ideal y de Divisa de Fisher (explicados abajo).

Los indices de Laspeyres y Pansche se construyen normalmente como medida ponderada de los índices relativos de cantidad de los componentes. Los pesos utilizados consisten en la participación de cada componente en el valor del output total en el periodo base (en el que también se basan los relativos de cantidad). Si se utilizan las participaciones iniciales, el indice es Laspeyres; si las terminales, Paasche.

20 Harley (1982). 


\section{CUADRO 2}

Estructura industrial 1841, 1815 y 1770

\begin{tabular}{|c|c|c|c|}
\hline Industria & 1841 & 1815 & 1770 \\
\hline \multicolumn{4}{|l|}{ Textiles } \\
\hline Algodón.....$\ldots \ldots \ldots \ldots \ldots$ & 0,10 & 0,08 & 0,01 \\
\hline Lana $\ldots \ldots \ldots \ldots \ldots \ldots \ldots \ldots$ & 0,08 & 0,11 & 0,15 \\
\hline Lino $\ldots . . . \ldots \ldots \ldots \ldots \ldots \ldots$ & 0,04 & 0,06 & 0,08 \\
\hline Seda $\ldots \ldots \ldots \ldots \ldots \ldots \ldots \ldots$ & 0,03 & 0,02 & 0,04 \\
\hline Vestido .......................... & 0,13 & 0,12 & 0,11 \\
\hline Cuero $\ldots \ldots \ldots \ldots \ldots \ldots \ldots \ldots \ldots$ & 0,11 & 0,14 & 0,19 \\
\hline Metal $\ldots \ldots \ldots \ldots \ldots \ldots \ldots \ldots \ldots \ldots \ldots \ldots \ldots$ & 0,11 & 0,08 & 0,05 \\
\hline Alimentación .................... & 0,04 & 0,06 & 0,08 \\
\hline Papel de impresión...$\ldots \ldots \ldots \ldots$ & 0.02 & 0.02 & 0,01 \\
\hline Minería $\ldots \ldots \ldots \ldots \ldots \ldots \ldots \ldots \ldots \ldots \ldots \ldots$ & 0,08 & 0.08 & 0,05 \\
\hline Construcción .................... & 0,18 & 0,15 & 0,12 \\
\hline Otras $\ldots \ldots \ldots \ldots \ldots \ldots \ldots \ldots \ldots \ldots \ldots \ldots \ldots \ldots \ldots$ & 0,09 & 0,09 & 0,12 \\
\hline
\end{tabular}

FUENTES: Harley (1982), p. 269.

los cambios en el precio relativo de los textiles de algodón y del hierro. Lógicamente esto me dio unas proporciones sectoriales coherentes para 1841, 1815 y 1770 . El «valor añadido» del algodón se reajustó para que reflejara unos precios relativos 1,8 veces más altos en 1815 que en 1841 y tres veces más altos en 1770 que en 1841. Para los reajustes del hierro utilicé un precio relativo de 18151,2 veces su nivel en 1841 y un precio para 17701,8 veces su nivel en 1841. Las estructuras industriales resultantes de estos cálculos se muestran en el cuadro 2. Inevitablemente, mis procedimientos para sustituir unos datos censales inexistentes en la industria manufacturera introducian un riesgo de error. El empleo y el valor añadido no se correspondían exactamente. Además, no intenté reajustar los cambios en los precios relativos excepto para el algodón y el hierro, sobre todo porque no existen datos fiables. Consideré, sin embargo, que las ventajas de usar la enumeración completa (bastante completa) de los censos y de mantener una clara consistencia entre los diferentes años eran mayores que las desventajas.

Poco después de que se publicara mi índice, N. F. R Crafts ${ }^{21}$ volvió a estimar independientemente la producción industrial. Sus datos sobre el crecimiento sectorial eran en su mayoría los mismos que los míos, pero él enfocó el

21 N. F. R. Crafts (1985), pp. 17.34. 
punto crucial de la ponderación de forma algo diferente. Mientras yo había intentado mantener la consistencia proyectando retrospectivamente la distribución del empleo/mano de obra industrial en 1841, y realizando ajustes concretos para los cambios en los precios relativos, Crafts se sirvió de estimaciones individuales del producto industrial a precios corrientes de 1770, 1801 y 1831 . Tanto Crafts como yo asignamos al algodón a finales del siglo XVIII un peso mucho menor que el que Hoffmann le habia asignado, pero la proporción que yo le atribui era bastante inferior a la de Crafts. Como era de esperar, mi indice agregado creció más lentamente que el de Crafts, y ambos lo hicieron más lentamente que el de Hoffmann.

\section{COMPARACION ENTRE LAS ESTIMACIONES ANTIGUAS Y LAS NUEVAS}

Hoffmann y Deane y Cole exageraron el crecimiento de la producción industrial y por tanto infraestimaron su nivel para el siglo xviI. La sobreestimación de Hoffmann se debió a las ponderaciones que utilizó para finales del siglo XVIII. Fijo la fecha base de 1783 para ponderar sectores de finales del siglo xviII. Estimó que los textiles de algodón constituyeron el 6,7 por ciento de la producción industrial -más o menos el peso asignado por Crafts, pero superior al mio-. Hoffmann estimó que los datos con que contaba sobre el output industrial cubrian el 56,4 por ciento de la producción industrial total. Para construir un índice tenia que estimar explícita o implícitamente el crecimiento del 43,6 por ciento restante. Lo hizo elevando proporcionalmente el peso de cada una de las industrias incluidas (por un factor 1,79-1/0,564). Esto elevó el peso de los textiles de algodón al 12 por ciento del índice. De forma implícita, pero incorrecta, el procedimiento de Hoffmann presuponía que algunas otras industrias, con el 79 por ciento de la magnitud de la algodonera, crecieron tan deprisa como el algodón.

Deane y Cole trabajaron de otra forma y utilizaron procedimientos distintos para los siglos XVII y XIX. Para el siglo XIX construyeron estimaciones de las rentas nominales por sectores. Estos cálculos combinaban estimaciones de rentas por trabajo basadas en el censo y estimaciones de rentas patrimoniales partiendo de las valoraciones del impuesto sobre la renta, aunque los datos existentes antes de la década de 1840 son poco fiables ${ }^{22}$. A continuación deflactaron estas estimaciones de la renta nominal con el índice de precios del

${ }^{22}$ Deane y Cole (1962), Caps. IV y V. 
FIGURA 1

Población y salarios reales en Inglaterra y Gales, 1250 - 1980

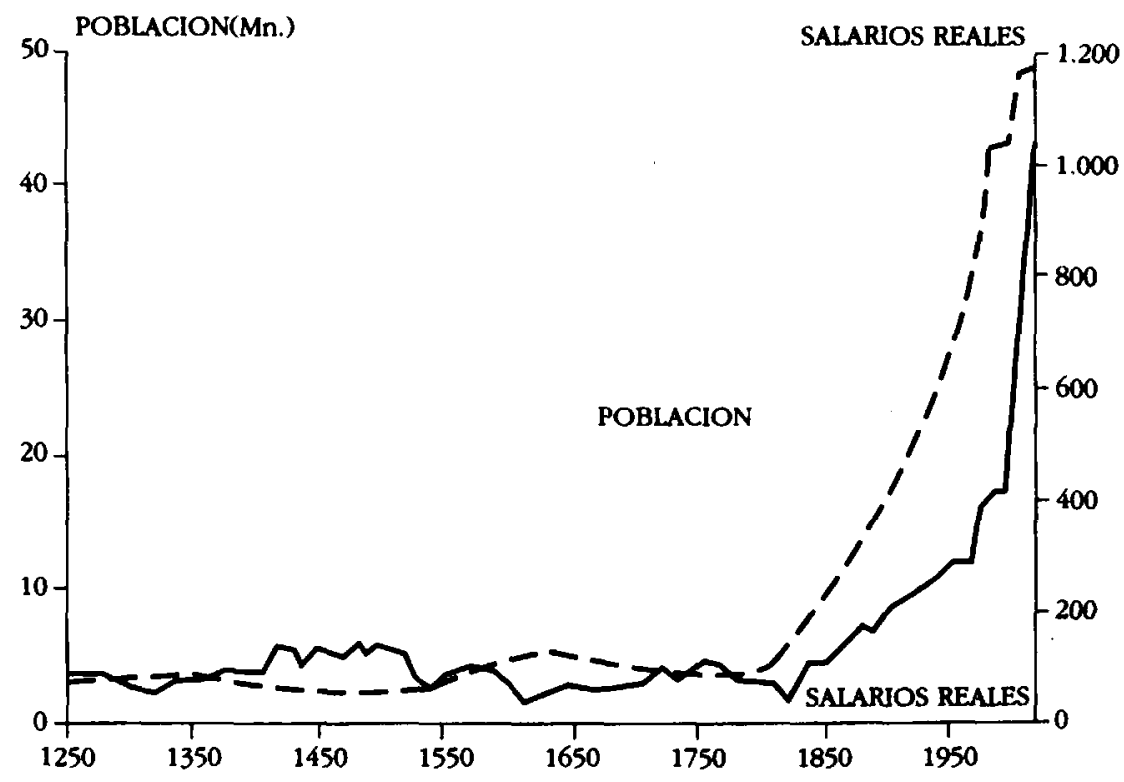

producto industrial de Rousseaux para estimar los volúmenes de producción. Desgraciadamente el indice de Rousseaux no representaba bien los precios industriales y exageraba la caída de los mismos a principios del siglo $\mathrm{XIX}{ }^{23}$. Para el siglo xvin, Deane y Cole dividieron el sector industrial en dos partes: el doméstico y el de exportación. La producción «doméstica» (una tercera parte del total en 1700) la estimaron por las series de los impuestos indirectos ${ }^{24}$. Consideraron que la base estadística directa para las industrias «de exportación» era inadecuada. Tras extensos estudios ${ }^{25}$ decidieron: «parece justo presuponer que el volumen de las exportaciones e importaciones nos proporcionará un indice razonablemente exacto del crecimiento de aquellas industrias que entraron a gran escala en el comercio exteriorw. El crecimiento del comercio en el siglo xvin les permitió la estimación del crecimiento de la producción industrial ade exportación», pero el procedimiento carece de una base teórica firme. Sobre

${ }^{23}$ Crafts (1985), pp. 30-31.

24 Deane y Cole (1962), p. 76.

2s Deane y Cole (1962), pp. 50-61. 


\section{CUADRO 3}

Indices de producción industrial agregada, 1700-1840

\begin{tabular}{|c|c|c|c|c|}
\hline & Harley & Crafts & Hoffmann & Deane \& Cole \\
\hline$\ldots \ldots \ldots \ldots \ldots$ & & 13 & 8 & 9 \\
\hline $1730 \ldots \ldots \ldots \ldots$ & & & 10 & 10 \\
\hline $1760 \ldots \ldots \ldots \ldots \ldots$ & & 19 & 12 & 14 \\
\hline $1770 \ldots \ldots \ldots \ldots$ & 23 & 4 & 13 & \\
\hline $1780 \ldots \ldots \ldots \ldots \ldots$ & & 25 & 16 & 15 \\
\hline $1790 \ldots \ldots \ldots \ldots$ & & & 23 & 18 \\
\hline $1801 \ldots \ldots \ldots \ldots \ldots$ & & 37 & 32 & 23 \\
\hline $1811 \ldots \ldots \ldots \ldots \ldots$ & & & 40 & 24 \\
\hline $1815 \ldots \ldots \ldots \ldots \ldots$ & 46 & & & \\
\hline $1821 \ldots \ldots \ldots \ldots \ldots$ & & & 51 & 57 \\
\hline $1831 \ldots \ldots \ldots \ldots \ldots$ & & 85 & 72 & 85 \\
\hline $1841 \ldots \ldots \ldots \ldots \ldots$ & 100 & 100 & 100 & 100 \\
\hline
\end{tabular}

FuENTEs: Crafts y Harley (1992), tabla 2 revisión de Harley (1982), p. 276, calculada a partir de la media de la banda de Divisia. Crafts (1985), p. 26, calculada empleando series con ponderaciones basadas en el promedio geométrico de años adyacentes (Divisia). Hoffmann (1955), apéndice; Deane y Cole (1963), calculado sobre datos de las pp. 78, 166. Los datos sobre precios corrientes, de Deane y Cole, han sido deflactados con el indice de precios industriales de Rousseaux.

todo, el procedimiento está socavado porque gran parte del crecimiento del comercio a finales del pasado siglo se dio con las Américas, donde la población aumentaba con más rapidez que en Gran Bretaña y en los demás paises y donde la guerra cerró temporalmente los mercados a los exportadores no británicos.

Unos datos incompletos hacen que sea imposible construir nada más preciso que unas *conjeturas controladas» sobre el crecimiento industrial durante la Revolución Industrial, pero el índice de Crafts y el mio probablemente definen los límites de las conjeturas aceptables. Por supuesto, se mantiene la incertidumbre; su fuente más importante es el peso de la producción de textiles de algodón en la agregación ${ }^{26}$. No obstante, ha quedado establecida la conclusión

26 Es posible que mi ponderación sea un poco baja por no haber contabilizado adecuadamente el valor añadido en la industria química y en otras industrias involucradas en el terminado de la téla de algodón y también quizá por una infraestimación del descenso de los precios de la tela de algodón en los primeros años de la industria. Crafts, en cambio, puede haber sobreevaluado el algodón. Ha reducido el peso que había asignado al algodón en 1831 para retirar la adquisición de insumos hecha por la industria (excluyendo el algodón en rama), pero por la inseguridad de las estimaciones base de la producción inicial de algodón, no los ha ajustado a los pesos anteriores. Véase Crafts y Harley (1992). Las nuevas cifras de Crafts están incorporadas a las tablas y figuras de este trabajo. 


\section{FIGURA 2}

Estimaciones de la producción industrial $(1841-100)$

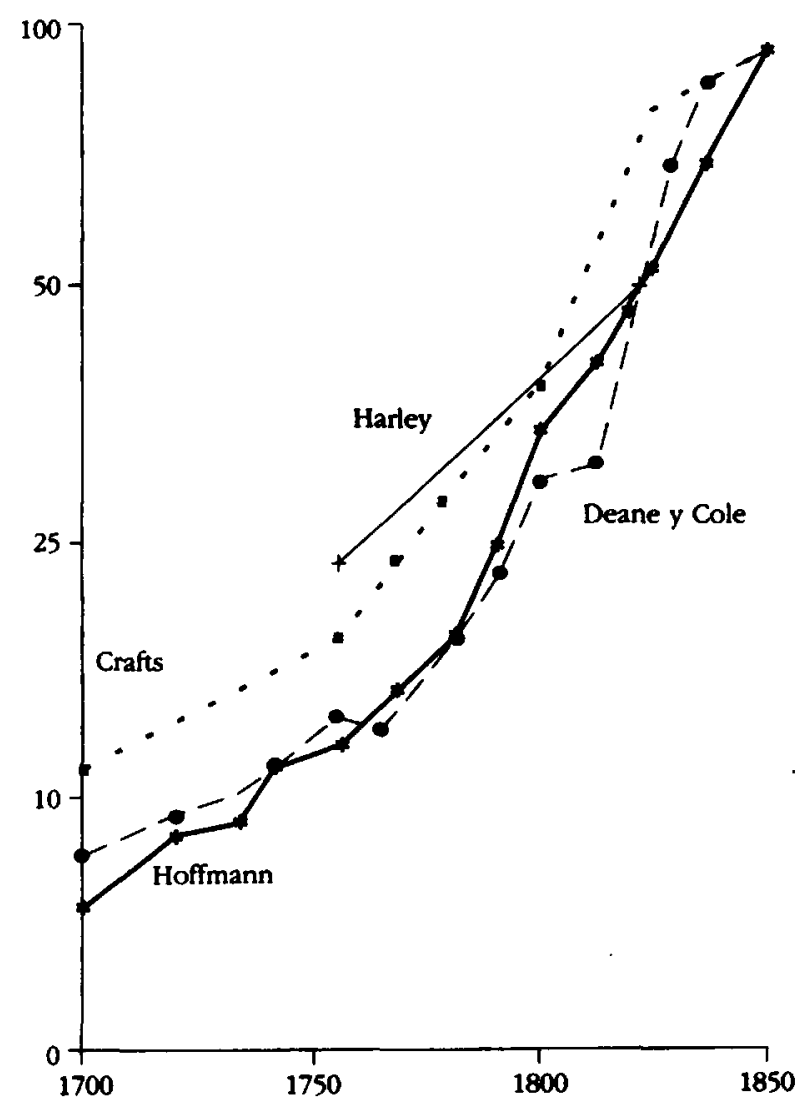

de que el crecimiento industrial fue mucho menor del que los historiadores económicos habian señalado hace una generación en base a las estimaciones de Hoffmann y Deane y Cole ${ }^{27}$. Yo calculé el crecimiento industrial entre 1770 y 1815 en un 1,6 por ciento anual o un 0,6 por ciento anual por habitan-

27 Crafts y Harley (1992). 
te. Crafts calculó un crecimiento más rápido: de alrededor de un 2 por ciento anual agregado y un 1 por ciento por habitante. Ambas estimaciones están muy por debajo de las de Hoffmann, que fueron de un 2,6 global y un 1,6 por habitante. Como mejor se aprecia la magnitud de las diferencias es comparando los niveles de la producción industrial por habitante en 1770 con los niveles de 1815. Mis cálculos implican una producción por habitante del 76 por ciento del nivel de 1815, los de Crafts del 64 por ciento y los de Hoffmann del 49 por ciento (ver Cuadro 3 y Figura 2).

La participación de la industria en la renta nacional queda en algo menos de un tercio entre las décadas de 1780 y $1830^{28}$. Esto significa que el crecimiento industrial generó un crecimiento de la renta por habitante de entre 0,02 y 0,03 por ciento anual. A este ritmo, la renta no se duplicaría hasta pasados entre doscientos y trescientos cincuenta años - lo cual no es una transformación repentina.

\section{La agricultura}

También la producción agricola ha de ser estimada partiendo de datos primarios imperfectos sobre precios, estimaciones de población y superficies cultivadas, productividades, tamaño de las cabañas ganaderas y peso medio por animal vendido ${ }^{29}$. Deane y Cole estimaron el crecimiento agricola en el siglo xviII presuponiendo que el consumo por habitante permaneció inalterado ${ }^{30}$. Su índice de producción era, por lo tanto, un indice poblacional ajustado a las importaciones netas de grano. Crafts señaló que este procedimiento era inadecuado porque la demanda de alimentos en las sociedades de renta baja tiene una considerable elasticidad/precio y renta que Deane y Cole no tuvieron en cuenta ${ }^{31}$. Los precios agrícolas relativos eran los mismos en 1760 que en 1700 , y Crafts, concediendo una elasticidad/renta en alimentos de 0,7 , estimó un crecimiento agrícola del 0,6 por ciento anual, aproximadamente un 0,2 por ciento

28 Crafts (1985), p. 45; Deane y Cole (1962), p. 166.

29 B. A. Holderness resume la opinión general de aquellos de nosotros que valiente o temerariamente hemos intentado estimar la producción agregada antes de que existiera la estadistica oficial (1989, p. 174):

-La sección de producción y productividad esti tan repleta de expresiones de duda, incertidum. bre $e$ incredulidad que se lee como una letania para escépticos. Evidentemente es necesario tener en cuenta el carácter dudoso de todas las eatimaciones de producción que no estén fundadas sobre la piedra angular de los resultados del censo agricola. No obstante, la precisión en el detalle no es esencial para la estimación de magnitudes probables o de la dirección de las tendencias.

30 Deane y Cole (1962), pp. 65, 74.

31 Deane y Cole (1976 y 1985), pp. 38-44. 
por encima del índice de crecimiento de la población. A partir de 1760 los precios agrícolas aumentaron con relación a otros precios, lo cual complicaba el análisis. Crafts utilizó dos procedimientos independientes para este periodo. A través del primero, deflactó las estimaciones de los valores corrientes de producción por un indice de precios agrarios. Con el segundo procedimiento, supuso una elasticidad precio de un 0,8 y una elasticidad renta de un 0,7 y obtuvo así simultáneamente estimaciones de la renta nacional y la producción agricola. Para los años comprendidos entre 1760 y 1800 los dos procedimientos generaron estimaciones similares: índices de crecimiento anual del 0,44 y el 0,50 , respectivamente. Para los años comprendidos entre 1800 y 1830, Deane y Cole deflactaron las estimaciones de la renta nominal y estimaron una tasa de crecimiento del 1,64 por ciento anual. Aunque sin rechazar esta estimación Crafts repitió para este período los procedimientos que había utilizado para el siglo xvin. Los resultados de los dos procedimientos empleados difirieron considerablemente; al deflactar obtuvo un crecimiento anual del 1,18 por ciento y las estimaciones de la demanda resultaron en un 1,88 por ciento. En sus trabajos subsiguientes Crafts ha utilizado la estimación más baja.

Los historiadores de la agricultura británica han presentado recientemente estimaciones independientes de la producción agraria agregada, basados en la historia de la producción ${ }^{32}$. Los agregados combinan superficie cultivada y estimaciones sobre el rendimiento por acre, y estimaciones del volumen de las cabañas y del peso medio por cabeza para la producción ganadera, en intervalos de cincuenta años desde 1700 hasta 1850 . En este siglo y medio estas estimaciones de la producción crecen aproximadamente al mismo ritmo que la estimación de Crafts: ésta mostraba una producción en 1700 alrededor de un 10 por ciento menos que las estimaciones de producción independientes. Las estimaciones de Holderness-Allen no intentan estimar movimientos a corto plazo pero plantean algunas dudas sobre la cronología del crecimiento agricola. Contrariamente a las conclusiones de Crafts - que dan un crecimiento inicial relativamente alto, casi un estancamiento durante más o menos una generación tras la mitad del siglo, y por último un crecimiento acelerado a principios del siglo xIX-, ellos señalan un crecimiento casi uniforme.

La estimación de Crafts sobre la producción agraria y el crecimiento de la productividad ha sido criticada tanto por la debilidad de su base probatoria ${ }^{33}$ como por su patente inconsistencia con las teorías generales sobre el crecimiento moderno. Jeffrey Williamson ha rechazado la teoria de que la agricul-

32 Allen (1991), véase Tabla 1, p. 35; Chartres (1985); Holderness (1989).

33 Mokyr (1987), pp. 305-317. 
tura avanzó en una magnitud similar a la del avance industrial, trazando analogias con la industrialización en los demás países: «La teoria de que los sectores modernos muestran unos índices mucho más rápidos del aumento de la productividad, mientras los sectores tradicionales se quedan rezagados, ha sido central en todos los informes sobre la industrialización, pasados y presentes». También ha indicado que las estimaciones de productividad hechas por Crafts no pueden encajar en una visión macroeconómica consistente de la Revolución Industrial ${ }^{34}$.

Al valorar las estimaciones agricolas es importante recordar que estamos proyectando retrospectivamente desde un conocimiento seguro del final del periodo. Mediado el siglo xIX la agricultura británica tenía la productividad más alta de Europa, empleando únicamente una pequeña proporción de los recursos nacionales y aun así alimentando a la mayoria de los británicos a pasar de las décadas de rápido aumento de la población. Si el crecimiento agrícola fue tan lento como sugieren algunos de los críticos de Crafts, la agricultura británica fue extraordinariamente productiva en la primera parte del siglo XviII y los británicos llegaron antes de ese periodo a la superioridad agricola. Pero la proporción de la población en las ciudades británicas no empezó a distanciarse de la del resto de Europa Occidental hasta el siglo XviI ${ }^{35}$.

La agricultura constituyó una gran parte de la economía británica del siglo xviI. Por lo tanto, las estimaciones del crecimiento agricola forman una parte importante de las estimaciones del desarrollo británico agregado anterior a la mitad del siglo xxx. Si el crecimiento agrario fue más lento en los cien años anteriores a 1850 de lo que ha estimado Crafts, entonces el crecimiento agregado también fue más lento. En conjunto, la nueva valoración de Crafts ha llevado ya a los historiadores económicos a la conclusión de que el crecimiento fue más lento de lo que se pensaba anteriormente. Un crecimiento agricola todavia más lento implica un nivel de vida británico todavia más alto a mediados del siglo xvin y una supremacia británica anterior. Si éste es el caso, los historiadores tendrán que dedicar su atención al cambio durante periodos an. teriores.

\section{Los servicios}

No se puede medir con ninguna exactitud el sector servicios - tarea difícil incluso en las economias modernas - a finales del siglo xvir. Deane y Cole di-

34 Crafts (1987a), pp. 273-274.

35 Wrigley (1986), p. 147. 


\section{FIGURA 3}

Renta nacional británica, 1700-1870

Renta total (millones de \$ USA 1970)

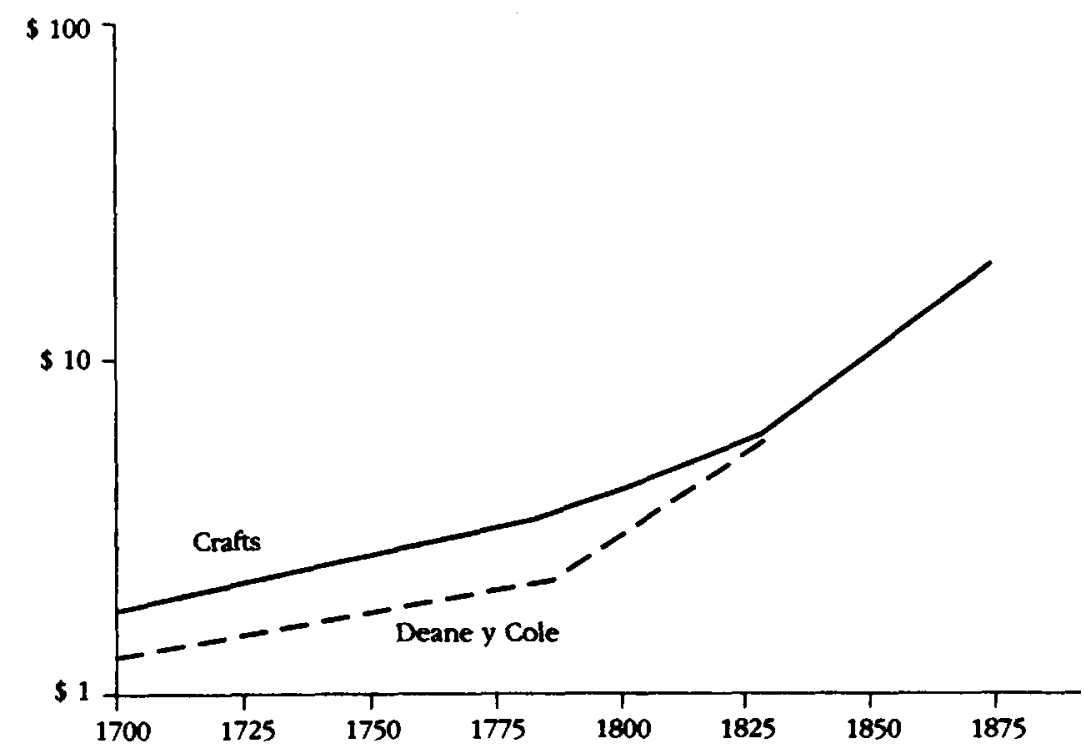

Renta per capita (\$ USA 1970)

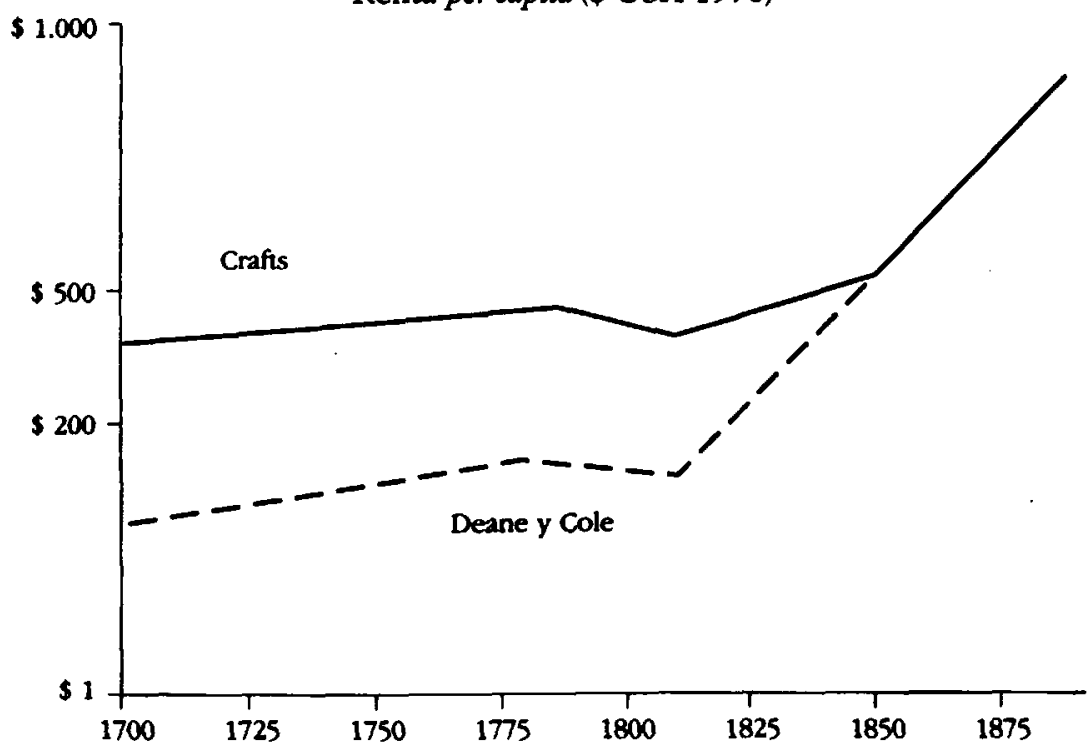


vidieron el sector servicios del siglo xvII en «gobierno y defensa» $y$ «rentas y servicios" y Crafts ha seguido apoyándose en estas estimaciones. Los gastos públicos registrados fueron deflactados por el indice de precios Schumpeter-Gilboy ${ }^{36}$. Se daba por sentado que las rentas y los servicios crecian con el crecimiento de la población. Crafts consideró también un sector comercial (que estaba incluido en la industria de Deane y Cole para el siglo xvIII) y supuso que creció al par que la renta nacional ${ }^{37}$. Para los primeros años del siglo XIX, Crafts rechazó la deflactación de Deane y Cole del valor corriente de la producción por el indice de precios de Rousseaux; según él, el deflactor era inadecuado y los resultados altamente improbables. En lugar de ello, él construyó unas estimaciones alternativas basadas principalmente en estimaciones del empleo ${ }^{38}$.

\section{La Renta Nacional}

La nueva evaluación de Crafts ha alterado de forma fundamental la imagen del crecimiento agregado. En el Cuadro 4 y Figura 3 se comparan los índices de la renta nacional de Crafts y Deane y Cole tanto en términos de agregación como por habitante. Deane y Cole muestran un desplazamiento hacia un crecimiento alto de la renta por habitante coincidiendo con las innovaciones textiles de finales del siglo Xvil. Los datos de Crafts no muestran tal desplazamiento. El crecimiento por habitante aumentó ligeramente alrededor de 1780 ó 1800, pero si hubo una ruptura en la tendencia, en lugar de una aceleración durante casi dos siglos, se produjo después de las Guerras Napoleónicas.

\section{UNA NUEVA VISION COHERENTE DEL DESARROLLO BRITANICO}

Los nuevos indicadores de la renta agregada proporcionan una visión coherente del crecimiento en Gran Bretaña, que contrasta con la que era aceptada anteriormente. La transformación industrial se ve ahora muy reducida a los

36 Jackson (1990) ha criticado los procedimientos de Crafts, pero sobreestimado la importancia de sus descubrimientos. No existe un procedimiento que sea demostrablemente «correcto» y la mayor diferencia que obtuvo fue de menos de dos décimas por ciento al año para el período comprendido entre 1760 y 1800 - una diferencia acumulativa del 8 por 100 debida a las diversas incertidumbres que contienen los cálculos.

37 Crafts (1985), p. 28.

38 Crafts (1985), pp. 34-37. 


\section{CUADRO 4}

Renta nacional, 1700-1870, Crafts y Deane y Cole

(US 1970 \$ según Crafts)

\begin{tabular}{lccccc}
\hline & Total (Mn.) & Per capita & Total (Mn.) & Per capite \\
\hline $1700 \ldots \ldots \ldots \ldots \ldots$ & 2,0 & 330 & 1,3 & 190 \\
$1760 \ldots \ldots \ldots \ldots \ldots$ & 3,0 & 400 & 1,9 & 250 \\
$1780 \ldots \ldots \ldots \ldots \ldots$ & 3,4 & 400 & 2,1 & 250 \\
$1800 \ldots \ldots \ldots \ldots \ldots$ & 4,5 & 430 & 3,2 & 310 \\
$1830 \ldots \ldots \ldots \ldots \ldots$ & 8,1 & 500 & 8,1 & 500 \\
$1870 \ldots \ldots \ldots \ldots \ldots$ & 23,6 & 900 & 23,6 & 900 \\
\hline
\end{tabular}

FueNTES: Crafts y Harley (1992), Cuadro 4. Deane y Cole (1962), pp. 78 y 106.

\section{CUADRO 5}

Fuentes del crecimiento 1700-1860. Estimaciones de Crafts (\% anual)

\begin{tabular}{|c|c|c|c|c|c|c|c|c|}
\hline & \multicolumn{4}{|c|}{ Tasa de crecimiento } & \multicolumn{4}{|c|}{ Contribución al crecimiento } \\
\hline & Renta & $K$ & $L$ & $T$ & $K$ & $L$ & $T$ & Residuo' \\
\hline $1700 \cdot 60 \ldots \ldots$ & 0,7 & 0,7 & 0,3 & 0,05 & 0,24 & 0,15 & 0,01 & 0,03 \\
\hline $1760-1800 \ldots$ & 1,0 & 1,0 & 0,8 & 0,2 & 0,35 & 0,40 & 0,03 & 0,2 \\
\hline $1801.31 \ldots \ldots$ & 1,9 & 1,7 & 1,4 & 0,4 & 0,60 & 0,70 & 0,06 & 0,5 \\
\hline $1831.60 \ldots \ldots$ & 2,5 & 2.2 & 1,4 & 0,6 & 0,70 & 0,70 & 0,09 & 1,0 \\
\hline
\end{tabular}

Notas: K - capital; L - trabajo; T - tierra. La participación de los factores para la estimación cs: capital, 0,35; trabajo, 0,5; tierra, 0,15.

FuENTES: Crafus y Harley (1992), cuadro 5 incluyendo el factor tierra. 
famosos sectores de la Revolución Industrial. El mayor crecimiento se dio en los textiles de algodón. Parte del crecimiento de la industria se debió a que los consumidores británicos compraran textiles de algodón, pero todavia más a que la industria británica se hiciera con los mercados textiles extranjeros. La economia británica se fue haciendo cada vez más industrial y urbana con el crecimiento del sector textil «moderno*. La máquina de vapor permitió que las hilanderías abandonaran la energia hidráulica y se instalasen en las ciudades, y los trabajadores urbanos y el capital se desplazaran de la agricultura rural a la industria urbana. La urbanización no se hizo sin fricciones, pero fue mucho más rápida en Gran Bretaña que en la mayoria de las sociedades que han realizado tal transición. Sin embargo, el aumento de la renta por el crecimiento de la industria urbana fue modesto. Gran parte de la industria urbana era simplemente una concentración de la actividad, y la exportación de dos tercios de la producción de algodón transfirió los beneficios del cambio tecnológico a los clientes extranjeros.

El cambio agrícola desempeñó una función importante, aunque su dimensión y cronologia exactas se encuentran ocultas en la complejidad de la economía rural. La tecnología agricola avanzó, desde luego, mucho menos que la de los principales sectores industriales, pero probablemente más que la de otros sectores industriales y de servicios. Además, la agricultura británica, probablemente por su estructura de clases, cedió su mano de obra y capital a los sectores en rápido crecimiento, en comparación con la historia de la industrialización en los demás países ${ }^{39}$. La mano de obra en el sector primario de la economia, aunque aumentó, descendió espectacularmente en proporción a toda la fuerza laboral: de un $\mathbf{4 0}$ por ciento en 1801 a sólo un 25 por ciento en la década de $1840^{40}$. Las demás economias europeas no llegaron a tener esta participación tan baja del empleo en el sector primario hasta un siglo después. En la mayoria de los paises, durante las primeras fases de la industrialización la mano de obra abandonó lentamente el sector primario, abriéndose una gran brecha de la productividad laboral entre la agricultura y la industria. En Gran Bretaña no se produjo tal diferencia. La estimación de Deane y Cole para 1840 muestra al 25 por ciento de la fuerza laboral dedicada al sector primario y una parte esencialmente similar de la renta $(24,9)$, producida por el sector. Para el mismo nivel de renta, el sector primario empleaba en la economía eu-

39 Esta hipótesis y los origenes de la relación entre las clases en la agricultura británica ha sido estudiada con alguna profundidad por Robert Brenner (1976).

40 Crafts (1987), p. 257. 
ropea media («la norma europeaw) el 54 por ciento de la fuerza laboral para producir el 37 por ciento de la renta ${ }^{41}$.

Desde 1770 hasta 1830, los años de la Revolución Industrial clásica, la renta real creció modestamente y el nivel de vida mejoró con lentitud. En las estimaciones de Crafts, el cambio relativamente rápido del gran sector agrícola (que a mediados del siglo XVIII constituía aproximadamente la mitad de la fuerza laboral y algo menos de la mitad de la renta, pero descendió rápidamente a principios del xIX) demostró ser tan importante para el desarrollo como la nueva tecnología industrial - que se limitaba a una parte relativamente pequeña de la economía (ni siquiera en 1841 sobrepasaba el 40 por ciento de la industria ni el 12 por ciento de la renta nacional).

Aunque el cambio económico que se produjo en Gran Bretaña a finales del siglo XVIII y comienzos del xIx fue más lento de lo que se pensaba anteriormente, marcó el comienzo del desarrollo económico moderno. La caracteristica básica de la economía pasó de ser el equilibrio tierra/población al cambio tecnológico y la acumulación de capital. El procedimiento empleado por Robert Solow (1956) para estimar las contribuciones de los factores al crecimiento del producto $e$ identificar un crecimiento «residual» debido al «cambio tecnológico» constituye el primer paso para explicar el crecimiento dentro de un marco neoclásico de agregación. El sistema presupone que puede representarse adecuadamente el output nacional como un agregado producido por una función de producción bien especificada. Se supone que la competencia da lugar a precios de los factores que son proporcionales al producto marginal de cada uno de ellos. En estas circunstancias, el crecimiento de la producción debido al crecimiento de un factor es igual a la tasa de crecimiento del factor multiplicado por su participación en la renta total. El «residuo» o «crecimiento total de la productividad del factor es la diferencia entre el indice de crecimiento de la producción medido y el crecimiento previsto por el aumento de los insumos ${ }^{42}$.

En el Cuadro 5 aparecen las fuentes usadas en los cálculos del crecimiento. $\mathrm{El}$ aumento en las tasas de crecimiento de los factores generó aproximadamente dos tercios de la aceleración del crecimiento de la producción entre los primeros años del siglo XVIII y los años centrales del siglo XIX. El aumento de la población se aceleró en las ültimas décadas del siglo xvin, y el ahorro y la in-

11 Crafte (1985), cep. 3.

42 Las restricciones para obtener una ecuación exacta de los residuos en relación con el cambio tecnológico ha llevado a muchos a cuestionar la relevancia del ejercicio (Berg y Hudson, 1991). A pesar de su indudable margen de error, estos cálculos parecen muy firmes (Crafts y Harley, 1992). 
versión mantuvieron el capital por persona en aproximadamente el nivel que tenía en 1760. Tanto en la industria como en la agricultura se produjo un aumento de la productividad. Si podemos creer en los cálculos ligeramente especulativos de Crafts, la productividad avanzó algo más deprisa en la agricultura que en la economia en su conjunto.

\section{CUADRO 6}

Contribución sectorial a la productividad

Crecimiento porcentual anual, 1780-1860

\begin{tabular}{|c|c|c|c|c|c|}
\hline & \multicolumn{3}{|c|}{ Estimación de MaCloskey } & \multirow[b]{2}{*}{ Praductividad } & \multirow[b]{2}{*}{ Contribución } \\
\hline & Participación & Productividad & Contribución & & \\
\hline Algodón ............ & 0,070 & 2,6 & 0,18 & 1,9 & 0,13 \\
\hline Estambre ..... & 0,035 & 1,8 & 0,06 & 1,3 & 0,05 \\
\hline Lana ........... & 0,035 & 0,9 & 0,03 & 0,6 & 0,02 \\
\hline Hierro .............. & 0,020 & 0,9 & 0,02 & 0,9 & 0,02 \\
\hline $\begin{array}{l}\text { Canales } \\
\text { y ferrocarriles ... }\end{array}$ & 0.070 & 13 & 009 & 13 & 009 \\
\hline Flota mercante ...... & 0,060 & 2,3 & 0,14 & $\begin{array}{l}1,3 \\
0,5\end{array}$ & $\begin{array}{l}0,07 \\
0,03\end{array}$ \\
\hline $\begin{array}{l}\text { Suma de los sectores } \\
\text { modernizados ... }\end{array}$ & 0,290 & 1,8 & 0,52 & 1,2 & 0,34 \\
\hline $\begin{array}{l}\text { Agricultura ............ } \\
\text { Todos los demás .... }\end{array}$ & $\begin{array}{l}0,270 \\
0,850\end{array}$ & $\begin{array}{l}0,4 \\
0,6\end{array}$ & $\begin{array}{l}0,12 \\
0,55\end{array}$ & $\begin{array}{l}0,7 \\
0,02\end{array}$ & $\begin{array}{l}0,19 \\
0,2\end{array}$ \\
\hline Total . & 1,410 & & 1,19 & & 0,55 \\
\hline
\end{tabular}

FuENTES: McCloskey (1981), p. 114, con las revisiones comentadas en el texto.

En un estudio hecho en 1981, Donald McCloskey reunió información correspondiente a diversas industrias y sectores en un interesante esfuerzo por encontrar «la localización de la inventiva». El crecimiento agregado de la productividad total de los factores - calculado restando al crecimiento estimado de la producción agregada, el crecimiento del insumo agregado- equivale a una media ponderada del crecimiento total de la productividad por factores de las industrias individuales. McCloskey realizó «estimaciones rudimentarias del cambio anual de la productividad por sectores" para varias industrias en proceso de modernización y para la agricultura ${ }^{43}$. Las estimaciones para estos

43 McCloskey (1981), pp. 108-117 y 124-127. 
sectores, una vez ponderadas, generaron un crecimiento de la productividad total agregada de los factores que apenas sobrepasaba la mitad de la productividad total por factores obtenida por cálculos agregados usando la estimación de la renta nacional de Deane y Cole. McCloskey atribuyó la restante productividad agregada de los factores a «todos los demás sectores» y concluyó que «de 1780 a 1860 la inventiva se extendia por toda la industria británica» ${ }^{44}$. La revisión de las estimaciones sobre la renta nacional alteran esta conclusión. En lugar del 1,19 por ciento anual que Deane y Cole asignaban al crecimiento de la productividad agregada, la revisión hecha por Crafts daba sólo el 0,55 anual. El crecimiento de la productividad que McCloskey estimó para los sectores modernos y la agricultura agota por completo la cifra de crecimiento obtenida por la agregación de Crafts ${ }^{45}$.

El estudio de McCloskey, aunque se trata de un precario e inseguro proceso de identificación de residuos, es extremadamente interesante y debe reconsiderarse con los nuevos agregados. El Cuadro 6 muestra nuevos cálculos (junto con los cálculos originales de $\mathrm{McCloskey} \mathrm{para} \mathrm{su} \mathrm{comparación)} \mathrm{que} \mathrm{incluyen} \mathrm{la}$ revisión de algunas de las estimaciones de la productividad industrial de McCloskey para retirar las sobreestimaciones del cambio de la productividad en varios sectores (algodón, lana y transporte maritimo) ${ }^{46}$. Aunque el crecimiento de la productividad en los sectores modernizados sólo se produjo a dos tercios del ritmo calculado por McCloskey, la contribución de estos sectores, junto con la estimación de Crafts sobre el cambio tecnológico agrícola, prácticamente agotan el cambio agregado de la productividad total por factores.

Según los cálculos agregados, el cambio tecnológico se redujo a la producción de textiles de algodón y de hierro y estos sectores eran demasiado pequeños para acelerar mucho el crecimiento agregado. Otras industrias apenas su-

44 McCloskey (1981), p. 117.

43 Crafts (1985), p. 86; (1987), p. 250.

46 McCloskey exageró el cambio en la productividad de los textiles de algodón por una sobreestimación del descenso de los precios de las telas de algodón (comparó el precio de una muselina de fantasia - un aterciopelado- en la década de 1780, con el de un percal de estampado corriente en 1860). El percal gris se vendía en las décadas de 1760 y 1770 por aproximadamente tres veces su precio (no 15 veces) a mediados del siglo xax (Harley, 1982, pp. 271 y 286-291). McCloskey atribuia en todo el período al estambre y las lanas el indice de crecimiento de la productividad correspondiente a los años comprendidos entre 1805 y 1860 . La historia de la indus. tria señala un avance tecnológico muy pequeño a principios del siglo XIX, por lo que el indice del cambio para todo el periodo debe ser rebajado. Por último, McCloskey utiliza la estimación del cambio de la productividad en el transporte maritimo del Atlántico Norte construida por North (1968) como estimación del cambio tecnológico en el transporte costero y oceánico. Un trabajo reciente (Harley, 1989) ha demostrado que en el transporte maritimo el cambio tecnológico fue mucho más lento. 
frieron cambios. Pero el crecimiento agregado fue sólo una parte del cambio ocurrido en Gran Bretaña. Un visitante que llegara a Manchester en la década de 1840 tendría razones para pensar que el cambio no había sido ni lento ni localizado. Ante èl, bajo el humo de las fábricas, se extendía un fenómeno -amenazador o prometedor según su punto de vista - que no habia existido cuando él era niño: una gran ciudad industrial mucho más pequeña, desde luego, que Londres, pero totalmente distinta. Aquí estaba una sociedad dominada no por la élite tradicional, sino por los dueños de las fábricas, y amenazada por un proletariado. Manchester albergaba una nueva industria, creada por la tecnologia de Arkwight, Crompton y Watt, ligada al comercio exterior tanto por sus materias primas como por sus ventas. Esta ciudad, creada por la nueva tec. nologia industrial y por el comercio (como Liverpool, Glasgow y Birmingham), sacudió los cimientos de la sociedad de la aristocracia británica. Su clase media, compuesta por propietarios de fábricas con creciente poder económico, ya habia forzado una reforma del Parlamento y se agitaba exigiendo el mercado libre. Sus empleados, el nuevo proletariado, exigia reformas más radicales de la Carta del Pueblo -el sufragio masculino; el voto secreto, distritos electorales iguales, la abolición de la condición de propietario exigida a los miembros del Parlamento; salarios para los miembros del Parlamento y reuniones anuales de los Parlamentos-. La Revolución Industrial habría aumentado con lentitud la renta por habitante, pero creó ciudades y clases que desafiaron al orden esta. blecido.

\section{CUADRO 7}

Producción y consumo de textiles de algodón: Efectos de las relaciones reales de intercambio

\begin{tabular}{|c|c|c|c|c|}
\hline & \multicolumn{2}{|c|}{ Cantidades } & \multicolumn{2}{|c|}{ Precios } \\
\hline & 1815 & 1841 & 1815 & 1841 \\
\hline $\begin{array}{l}\text { Producción } \ldots \ldots \ldots \ldots \ldots \ldots \\
\text { Algodón en rama } \ldots \ldots \ldots \ldots \ldots \\
\text { Consumo: } \\
\quad \text { Algodón } \ldots \ldots \ldots \ldots \ldots \ldots \\
\text { Importaciones } \ldots \ldots \ldots \ldots\end{array}$ & $\begin{array}{r}100 \\
25 \\
40 \\
35\end{array}$ & $\begin{array}{l}520 \\
236,5 \\
208 \\
75,5\end{array}$ & $\begin{array}{l}1,0 \\
1,0\end{array}$ & $\begin{array}{l}0,5 \\
1,0\end{array}$ \\
\hline $\begin{array}{l}\text { Consumo agregado: } \\
\text { Precios de } 1815 \ldots \ldots \ldots . \\
\text { Precios de } 1841 \ldots \ldots \ldots .\end{array}$ & $\begin{array}{l}75 \\
55\end{array}$ & $\begin{array}{l}283,5 \\
179,5\end{array}$ & Indice, & -100 \\
\hline
\end{tabular}

FuENTE: Véase texto. 
La industria, sobre todo la del algodón, de cuya producción aproximadamente dos tercios eran destinados al extranjero, logró un fuerte aumento gracias a la exportación. En 1840 las cifras de población de Manchester y Liverpool se aproximaban al medio millón; más o menos el mismo número de personas habitaban las demás ciudades textiles de Lancashire. Una urbanización similar, aunque algo menos intensa, basada en el algodón, se habia producido en las tierras bajas del oeste de Escocia. El hierro tuvo menos impacto. Birmingham, el centro de la fabricación del metal, habia crecido con rapidez, pero seguía siendo alrededor de un 25 por ciento menor que Liverpool o Manchester.

En los primeros años del reinado de la reina Victoria, las firmas británicas dominaban la industria moderna del mundo ${ }^{47}$. Muchos contemporáneos e historiadores han hablado de un monopolio británico. Pero aunque hubo dominio británico, no hubo monopolio; aquello fue más bien un capitalismo competitivo. Las empresas entraban con facilidad en la industria algodonera y vendían en mercados competitivos. No pudieron impedir que los precios cayeran hacia los costes de producción. Los beneficios del cambio tecnológico fueron para los consumidores en forma de precios más bajos. La estructura competitiva de la industria textil del algodón significó que mientras el mundo salía beneficiado por las mejoras en la tecnologia británica, Gran Bretaña ganaba muy poco más con aquellas exportaciones.

Gran Bretaña exportaba algodones para obtener materias primas y productos alimenticios. En los veinticinco años que siguieron a las Guerras Napoleónicas, el cambio tecnológico redujo casi a la mitad la mano de obra y el capital necesarios para fabricar en Lancashire una pieza de algodón. El mercado competitivo causó un descenso de los precios y en 1840 con una pieza de tela exportada sólo podía adquirirse la mitad de los productos alimenticios que se habian adquirido al final de la guerra. El mismo cambio tecnológico que había generado el crecimiento de la industria hizo que la relación de intercambio se deteriorase.

Puesto que las alteraciones de los precios transfirieron los beneficios del cambio tecnológico a los consumidores extranjeros, la agregación convencional sobreestima los beneficios que obtuvo Gran Bretaña del crecimiento de la industria algodonera. Los cálculos que aparecen en el Cuadro 3 ilustran estos órdenes de magnitud. En 1841 Gran Bretaña produjo 5,2 veces tantos textiles de algodón como había producido en 1815. En ambos años se exportó aproxima-

47 Bairoch (1982) estima que Gran Bretaña contenia mis de la mitad de la industria moderna en 1840. Gran Bretaña adquirió el 55 por ciento de la producción mundial de algodón en rama y participó considerablemente más en el valor de su producción, por la media más elevada que daba la hilatura realizada en Gran Bretaña (Ellison, 1886, pp. 100, 146). 
damente el 60 por ciento de la producción. Piénsese que con estas exportaciones se pagaba en primer lugar el algodón en rama importado y después la importación de un conjunto representativo de bienes de consumo. En 1815 las importaciones de algodón en rama costaron aproximadamente una cuarta parte del valor total de la producción; en 1841 la proporción fue ligeramente más alta, de un 31 por ciento. En 1815 el 35 por ciento de la producción se exportó a cambio de bienes de consumo extranjeros. En 1841 alrededor del 29 por ciento se exportó a cambio de bienes de consumo extranjeros $-4,3$ veces los textiles que en 1815-. Pero con una pieza de tela de algodón ahora sólo se podía adquirir la mitad de las importaciones. La cantidad de algodón producido aumentó 5,2 veces, pero el consumo que este aumento (de productos de algodón y de importación) facilitó a los consumidores británicos aumentó únicamente unas tres veces o tres veces y media $(3,8$ veces si el algodón y las importaciones se valoran a los precios de 1815 , ó 3,3 veces si se valoran a los de 1841). Asi pues, las exportaciones tuvieron un impacto directo pequeño sobre la renta nacional. Pero al mismo tiempo aumentaron en gran medida el volumen de la industria y su impacto social.

La revisión de las estimaciones agregadas básicas del crecimiento británico, combinada con un enfoque neoclásico, nos da una visión general de los cambios producidos en la economía británica durante los años finales del siglo xvin y primeros del xix ${ }^{48}$. Los cambios revolucionarios de la industria se redujeron en gran parte a los famosos sectores textil, siderúrgico y del transporte. Incluso combinados, su cambio tecnológico no contribuyó sino modestamente al crecimiento del output agregado. La famosa tecnologia industrial produjo un crecimiento de la renta nacional de alrededor de un 0,3 por ciento anual. Esto requeriría dos siglos para que la renta se duplicase. No obstante, el cambio industrial colaboró al cambio de la estructura social, del comportamiento demográfico y del hábito del ahorro. Por supuesto sigue siendo posible que estos cambios sociales estimularan el crecimiento. Pero de todas formas, no parece posible mantener la teoria de que las innovaciones en la hilatura del algodón revolucionaron el desarrollo británico en el curso de una generación.

Las nuevas estimaciones de la renta nacional revelan un largo periodo de transición. Probablemente el crecimiento comenzó a acelerarse en los últimos años del siglo XVII o primeros del XVII. $A$ finales del siglo XvIn tuvieron lugar importantes innovaciones en algunas industrias, pero el crecimiento de la renta nacional por persona se aceleró muy poco. El cambio agrícola acelerado con-

4. La consistencia interna de esta teoria está confirmada por cälculos basados en un modelo computable de equilibrio general. 
tribuyó casi tanto como la innovación industrial. El desarrollo económico moderno no quedó plenamente establecido en Gran Bretaña hasta la era del ferrocarril.

A pesar del moderado impacto de la tecnologia industrial sobre el crecimiento agregado, los cambios en la actividad económica alteraron profundamente la estructura social británica. En la década de 1830, una combinación del rápido crecimiento de las industrias textiles con base urbana, que exportaban la mayor parte de su producción, y el descenso en la participación de la fuerza laboral en la agricultura, dio lugar a la primera economía industrial urbana. Tanto la tecnología industrial como el flujo laboral saliente de la agricultura fueron importantes. El rápido cambio tecnológico ocurrido en los textiles y el hierro llevó a unos descensos espectaculares de los precios que dieron a los productores británicos la ventaja, rápidamente aprovechada, de poder cubrir una gran parte de la demanda mundial en estas industrias. En la década de 1840 , los productores británicos de algodón exportaron más o menos el sesenta por ciento de su producción ${ }^{49}$. La industria siderúrgica exportó la cuarta parte de su producción y la industria lanera aproximadamente el veinte por ciento 50 .

La transformación británica requería tanto una movilidad de la mano de obra y de otros factores de producción, que se desplazara desde la agricultura a la industria, como mejoras en la tecnologia industrial. En términos históricos, los británicos se adaptaron con mucha rapidez. Probablemente el alto nivel del cambio tecnológico agrícola, el rápido aumento de la producción y la transferencia de la mano de obra surgieron de la estructura social de la Gran Bretaña rural. En la agricultura una gran parte tanto de los hombres de empresa como de la mano de obra era ajena a la propiedad de la tierra. Esta separación de la mano de obra de los medios de producción hizo a la primera muy sensible a los estímulos del mercado.

\section{LA DISTRIBUCION DE LAS RENTAS: UN ENFOQUE ALTERNATIVO}

Los contemporáneos, desde los economistas clásicos hasta los reformadores radicales, prestaron mucha atención a la distribución. Vieron la industrialización como un proceso que en primer lugar enriqueció a las clases propieta-

49 Ellison (1886), p. 60 .

so Deane y Cole (1962), pp. 196-225. 
rias, mientras en el mejor de los casos pasó de largo ante la clase trabajadora y más probablemente hundió en la miseria a una parte del proletariado. Hace una generación, los datos agregados parecían indicar una redistribución considerable perjudicial para la clase trabajadora. Deane y Cole estimaron la renta por habitante en 2,4 veces su nivel de 1780, pero el indice de salarios reales de Phelps Brown y Hopkins lo aumenta sólo en un 30 por ciento (1956).

Recientemente, Peter Lindert y Jeffrey Williamson han seguido la evolución de la distribución de la renta a partir del siglo xvi, reconstruyendo y mejorando las estimaciones de los ingresos de las diversas clases hechas por diversos contemporáneos ${ }^{51}$. Las distribuciones de la renta mostraban unos altos niveles de desigual en comparación con los de la Gran Bretaña moderna y de otros paises desarrollados, y también, aunque la diferencia es menos aguda, con los de otras sociedades de finales del siglo xix. Las mediciones indicaban que la desigualdad aumentó entre finales del siglo xvil hasta mediados del $\mathrm{xxx}$, antes de empezar a bajar a los niveles del siglo $\mathrm{xx}$-una configuración de aumento y después descenso de la desigualdad al producirse el crecimiento que se conoce como ala curva de Kuznetsw 52.

Pero las mediciones de Lindert y Williamson no representan correctamente las distribuciones de la renta. E. H. Phelps Brown ha analizado sus datos recientemente utilizando la técnica de los «Pen parades», que ilustra mejor las experiencias de diversos grupos de renta 53 . La conclusión a que llega es que los cambios en las estimaciones de la distribución de la renta pueden verse como un proceso continuado (aunque durante las Guerras Napoleónicas los muy pobres perdieron y los muy ricos ganaron). El caracteriza el cambio de

31 Lindert (1980, 1986), Williamson y Linder (1982, 1983a). Williamson presentó también datos de salarios para diversas ocupaciones que indicaban una creciente desigualdad (1985, Caps. 2 y 3). La valoración critica ha desacreditado grandemente estos datos (Feinstein, 1988b; Jackson, 1987).

32 Esto significa una modificación de una teoria anterior (Soltow, 1968; O'Brien y Engerman, 1982) que partiendo de las mismas fuentes concluyó que la distribución de la renta no cambió de manera significativa antes del siglo $x x$. Las estimaciones de Lindert y Williamson muestran una menor desigualdad en los primeros años, principalmente por la revisión de las cifras ocupacionalea que da la investigación de Lindert en el registro de enterramientos (Lindert, 1980). Craftes ha señalado que las cifras basadas en King son especialmente inseguras y es muy posible que infravaloren la desigualdad al no considerar los bajos salarios que prevalecian en el norte (1989, p. 87).

"s Los «Pen paradesw, que deben su nombre al economista holandés Jan Pen, que los ideó, son gráficos de niveles de rente individual contrastados con percentiles de la distribución de ha renta. Para un comentario sobre la interpretación de la distribución de la renta, véase Phelps Brown (1988), cap. 9. 
manera distinta a la de Williamson y Lindert y sus conclusiones son dignas de mención en detalle ${ }^{54}$ :

En suma, la estructura de las rentas ha cambiado entre 1688 y 1867 , pasando de tres escalones muy marcados a un suave escalonamiento. Caracterizar de esta forma la estructura de 1688 es simplificarla demasiado; pero al contrario que la estructura posterior, sí parece formada por tres grupos - los campesinos, que constituian la mitad del número total de perceptores de rentas; «la aristocracia del trabajo», los artesanos, y con ellos los propietarios de tierras y los profesionales un grupo medio con rentas sustancialmente más elevadas que las de los trabajadores, en pronunciado aumento dentro de sus limites; y en la cúspide algunas rentas realmente muy altas. En 1867 este panorama habia cambiado notablemente. El grupo inferior habia aumentado en relación con los otros y difería menos en su composición. El grupo medio no se diferenciaba ya de forma tan aguda de los de abajo, ni en el ritmo a que aumentaban sus rentas, ni como parte proporcional de la renta total. Hasta aquí, el movimiento habia sido hacia una mayor igualdad. Pero en relación con los otros dos, el grupo de la cúspide se habia hecho más rico que nunca. Las «Pen parades» sirven para mostrar y localizar estos diversos cambios, en cuya presencia cualquier medición de la desigualdad significa poco.

Los historiadores saben desde hace mucho que dentro de las clases trabajadoras se produjo una gran variedad de experiencias. En el norte las rentas fueron inicialmente bajas, pero subieron mucho más deprisa que en el sur. Las posibilidades industriales aumentaron más que las posibilidades agricolas. La tecnologia industrial empobreció a algunos, sobre todo al cuarto de millón de tejedores manuales del algodón, mientras creó una «aristoctacia laboraln de trabajadores cuya pericia se hacía más valiosa con el cambio tecnológico "s. Los mercados de trabajo y de capital se segmentaron en los aspectos regional, industrial y de clase y no obtuvieron rendimientos iguales a lo largo de la economía. Unos mercados de factores más eficientes hubieran aumentado el output, tal vez considerablemente $\%$. Pero las ineficiencias no se originaron en el siglo xvill y probablemente se redujeron, a pesar de las marcadas diferencias del impacto regional que causó el cambio tecnológico.

Para conocer plenamente la transición británica hacia un desarrollo económico moderno hay que considerar la segmentación del mercado por regiones, clases, costumbres y otras fuentes de inercia. El cambio rápido alteró la distribución de la renta. Durante largos periodos de desequilibrio, algunos sectores

I4 Phelps Brown (1988), pp. 314-315.

35 En varios lugares, Crafts ha llamado la atención sobre los problemas regionales (1982; 1985, pp. 104-107; 1989).

36 Williamson (1987b). 


\section{CUADRO 8}

Modelo computable de equilibrio general

\begin{tabular}{|c|c|c|}
\hline & Año base 1841 & Estimación 1770 \\
\hline \multicolumn{3}{|l|}{ Cantidades: } \\
\hline \multicolumn{3}{|l|}{ Producto británico: } \\
\hline Industria moderna $\ldots \ldots \ldots \ldots \ldots \ldots \ldots \ldots \ldots$ & 12,4 & 1,8 \\
\hline Otra industria $\ldots \ldots \ldots \ldots \ldots \ldots \ldots \ldots \ldots \ldots$ & 22,0 & 9,9 \\
\hline 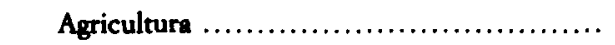 & 22,1 & 8,2 \\
\hline Servicios $\ldots \ldots \ldots \ldots \ldots \ldots \ldots \ldots \ldots \ldots \ldots \ldots \ldots \ldots \ldots \ldots$ & 43,5 & 17,6 \\
\hline \multicolumn{3}{|l|}{ Participación factorial británica: } \\
\hline Trabajo $\ldots \ldots \ldots \ldots \ldots \ldots \ldots \ldots \ldots \ldots \ldots \ldots \ldots \ldots \ldots \ldots \ldots$ & 53,1 & 22,8 \\
\hline 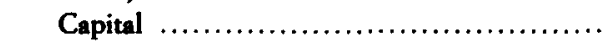 & 38,1 & 16,4 \\
\hline Tierras $\ldots \ldots \ldots \ldots \ldots \ldots \ldots \ldots \ldots \ldots \ldots \ldots$ & 8,8 & 8,8 \\
\hline \multicolumn{3}{|l|}{ Producto del resto del mundo: } \\
\hline Industria moderna $\ldots \ldots \ldots \ldots \ldots \ldots \ldots \ldots$ & 11,2 & 11,2 \\
\hline Otra industria $\ldots \ldots \ldots \ldots \ldots \ldots \ldots \ldots \ldots \ldots \ldots \ldots \ldots$ & 126,4 & 128,3 \\
\hline Agricultura $\ldots \ldots \ldots \ldots \ldots \ldots \ldots \ldots \ldots \ldots \ldots \ldots \ldots \ldots$ & 297,0 & 293,7 \\
\hline Servicios $\ldots \ldots \ldots \ldots \ldots \ldots \ldots \ldots \ldots \ldots \ldots \ldots$ & 219,2 & 216,8 \\
\hline \multicolumn{3}{|l|}{ Participación factorial del resto del mundo: } \\
\hline Trabajo $\ldots \ldots \ldots \ldots \ldots \ldots \ldots \ldots \ldots \ldots \ldots \ldots$ & 332 & 332 \\
\hline 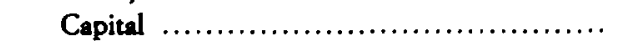 & 205 & 205 \\
\hline Tierras $\ldots \ldots \ldots \ldots \ldots \ldots \ldots \ldots \ldots \ldots \ldots \ldots$ & 120 & 120 \\
\hline \multicolumn{3}{|l|}{ Comercio britannico: } \\
\hline Exportaciones modernas $\ldots \ldots \ldots \ldots \ldots \ldots \ldots$ & 6,8 & 0,9 \\
\hline Importaciones, agricultura ................. & 6,8 & 2,0 \\
\hline \multicolumn{3}{|l|}{ Precios: } \\
\hline Industria moderna $\ldots \ldots \ldots \ldots \ldots \ldots \ldots \ldots \ldots \ldots$ & 1,00 & 2,11 \\
\hline 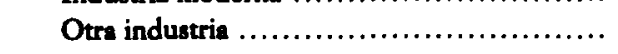 & 1,00 & 0,76 \\
\hline Agricultura ................................ & 1,00 & 1,00 \\
\hline Servicios ................................ & 1,00 & 0,76 \\
\hline 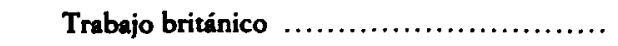 & 1,00 & 0,76 \\
\hline Capital britanico $\ldots \ldots \ldots \ldots \ldots \ldots \ldots \ldots \ldots \ldots \ldots$ & 1,00 & 0,75 \\
\hline Tierra británica $\ldots \ldots \ldots \ldots \ldots \ldots \ldots \ldots \ldots$ & 1,00 & 0,37 \\
\hline Utilidad británica per capita ....................... & 100 & 88 \\
\hline
\end{tabular}


en crecimiento obtuvieron extraordinarios beneficios y algunos sectores en decadencia padecieron dificultades extraordinarias. Los nuevos equilibrios se caracterizaron por unas distribuciones alteradas de la renta. La variedad regional e industrial tiende a verse oscurecida en las valoraciones macroeconómicas agregadas y requieren un continuado y cuidadoso estudio para conocer plenamente las fuentes y las consecuencias de la Revolución Industrial ${ }^{57}$.

\section{¿Por qué fue tan lento el crecimiento? La guerra y la naturaleza} del crecimiento británico

El crecimiento económico británico no se aceleró sino gradualmente en el siglo xIx. En comparación con el crecimiento inicial de otros paises ahora avanzados, el crecimiento británico fue lento; más lento de lo que anteriormente se pensaba. Jeffrey Williamson ${ }^{58}$ ha indicado que Gran Bretaña creció más despacio que otras sociedades industriales más recientes, sobre todo por los veinticinco años de guerra con la Francia revolucionaria y con Napoleón. Con su visión plantea Williamson dos cuestiones importantes: ¿Cuál fue la naturaleza del crecimiento británico inicial, especialmente en comparación con la aparición del desarrollo moderno en otros países? Y, si las Guerras Napoleónicas jugaron un papel importante y costoso en la historia de aquel periodo, ¿qué impacto tuvieron?

\section{Teorias globales distintas sobre el desarrollo británico}

Crafts y Williamson han comparado las teorias básicamente diferentes sobre el desarrollo británico con el desarrollo que se inició más tarde en otros países. La hipótesis de Williamson es que el crecimiento económico moderno se inició siguiendo un patrón general, aplicable a las economias contemporáneas del Tercer Mundo, a los Estados Unidos en el siglo xIX y a Japón en el $\mathrm{xx}$. Estos ejemplos le llevaron a señalar que la modernización comienza en general con un rápido crecimiento y con especial énfasis en la manufactura. Que en el impulso inicial, la productividad, debe crecer rápidamente en los sectores modernos, y la formación de capital acelerarse, lo que da por resultado un cre-

57 Berg y Hudson (1992).

s8 Williamson (1985, 1987a). 
cimiento rápido. Pensaba que sólo el esfuerzo de la guerra desvió a Gran Bretaña de la norma general $\$ 9$.

Crafts partió de una visión fundamental distinta que subrayaba las diferencias entre Gran Bretaña y las economías europeas de industrialización posterior ${ }^{60}$. Para él, los Estados Unidos, Japón y el mundo contemporáneo no presentan analogias convincentes. Gran Bretaña fue la pionera de la industrialización durante un largo periodo, en el que fueron emergiendo lentamente las instituciones y tecnologias adecuadas. A finales del siglo xviII tuvieron lugar cambios revolucionarios en unas cuantas industrias manufactureras -sobre todo en los textiles y en el hierro-, pero los cambios no fueron generales. La mayor parte de los productos del metal y de casi todos los demás productos industriales seguian fabricándose como en los antiguos tiempos. Los datos, aun siendo como son imperfectos, indican que la agricultura, lejos de ser un sector rezagado como en muchas industrializaciones posteriores, experimentó un cambio tecnológico más rápido que la mayor parte de la economia, con excepción de las nuevas industrias.

Desde el punto de vista de Crafts, la aparición lenta del desarrollo británico fue natural. Pero desde el punto de vista de Williamson, el lento crecimiento durante la afase heroica de la Primera Revolución Industrial» requeria ser estudiado. Comentó ${ }^{61}$ :

incluso durante la desaceleración de la productividad, la crisis del petróleo, los obstáculos maltusianos y la escasez de capitales en el extranjero, en la década de 1970 el Tercer Mundo logró unos indices de crecimiento anual de la renta per capita de aproximadamente el 3,2 por ciento. ¡Diez veces el de Gran Bretaña antes de 1820 !

\section{Además,}

Gran Bretaña era una ahorradora lenta... el ritmo de acumulación de capital fue tan pequeño que apenas se produjo ningún incremento en la intensidad de su uso.

Williamson señaló que Gran Bretaña creció con lentitud porque «intentó hacer dos cosas al mismo tiempo -industrializarse y combatir en unas guerras costosas - y sencillamente carecia de los recursos necesarios para hacer las dos de forma eficaz». En especial, veía a la deuda pública emitida por los go-

\footnotetext{
39 Crafts y Williemson (1985), pp. 87-90, 183; (1987a), pp. 269-270, 272.273.

60 Crafts (1985), Cap. 3.

61 Williamson (1985), p. 162.
} 
biernos de tiempos de guerra como causante del retraimiento de la inversión productiva. En ausencia de guerras, creia que la formación de capitales, el cambio estructural y el crecimiento hubieran sido mucho más rápidos, según las pautas normales de la primera industrialización.

\section{La guerra}

Las guerras con Francia complican mucho el análisis de la revolución industrial británica, y desde luego Williamson tenia razón al insistir en que no deben dejarse a un lado. La Francia revolucionaria declaró la guerra a Gran Bretaña en 1793 y los combates continuaron con intensidad hasta la derrota definitiva de Napoleón en 1815. El conflicto fue una de las grandes guerras de la historia, la conclusión del épico enfrentamiento entre Inglaterra y Francia, que había comenzado en 1689. En los 126 años transcurridos entre esta fecha y 1815 , Inglaterra estuvo en guerra en 73 de ellos, y en todos éstos menos dos, contra Francia. La Figura 4 sumariza los gastos de guerra británicos en relación con el PNB. Fueron guerras a gran escala; las Guerras Napoleónicas destacan no tanto por su intensidad - las luchas anteriores se habian llevado más o menos la misma proporción de la renta nacional-como por su duración.

Patrick O'Brien ha estudiado recientemente el impacto que tuvo el estado hanoveriano sobre la economía británica. Durante el siglo Xvil la moderna nación-estado surgió de los conflictos que se generaron por las ambiciones continentales de Francia y la oposición británica. Al final, con el Tratado de Viena y la restauración de la monarquia francesa, los británicos quedaron satisfechos: la lucha había sido costosa, pero sus intereses vitales habian sido defendidos y aumentados. Aunque no como potencia dominante en la Europa continental, Gran Bretaña aparecia como la mayor potencia mundial. O'Brien resume así el balance económico:

Se miren como se miren, los gastos de las fuerzas armadas necesarios para apuntalar la política extranjera y estratégica del reino, parecen masivos, y posiblemente despilfartadores. En el aspecto positivo, entre 1688 y 1815 la economía nacional no había sido destruida por las invasiones. Antes de 1805, no surgió en el continente europeo ninguna gran potencia capaz de obstaculizar el comercio del reino con el continente. La agresión extranjera contra el comercio británico y los territorios de ultramar se habia reducido significativamente. Tras el reconocimiento de su independencia en 1783, los Estados Unidos se habian ureincorporadow a la economia atlántica que tenia por centro a Gran Bretaña. Mientras tanto la diplomacia, respaldada por la fuerza militar, habia obligado a 
los imperios rivales de Portugal, España y Holanda en Sudamérica y Asia y a los Mongoles en la India, a conceder entrada al comercio y los barcos británicos.

Por supuesto, la guerra era cara, y sus costes - los hombres y el equipamiento requerido y los desequilibrios de la economia - tenian que afrontarse en términos reales antes de que se produjeran o cuando se producian por medio de emisiones de títulos. Es útil, por lo tanto, considerar la teoría de Williamson, según la cual los gastos militares desviaron sobre todo recursos de la inversión, frenando seriamente el crecimiento ${ }^{62}$. Algunos costes se afrontaron antes del conflicto - se entrenaron tropas y se fabricó equipamiento que se almacenó en tiempos de paz-. Pero la Figura 4 muestra que el gobierno tuvo que conseguir grandes cantidades de recursos para uso militar una vez iniciadas las hostilidades. Habia cuatro posibles fuentes de recursos: (I) del extranjero (II)

\section{FIGURA 4}

Gastos militares y renta nacional, $1690-1830$

(precios constantes, promedio de 1720 - 1774)

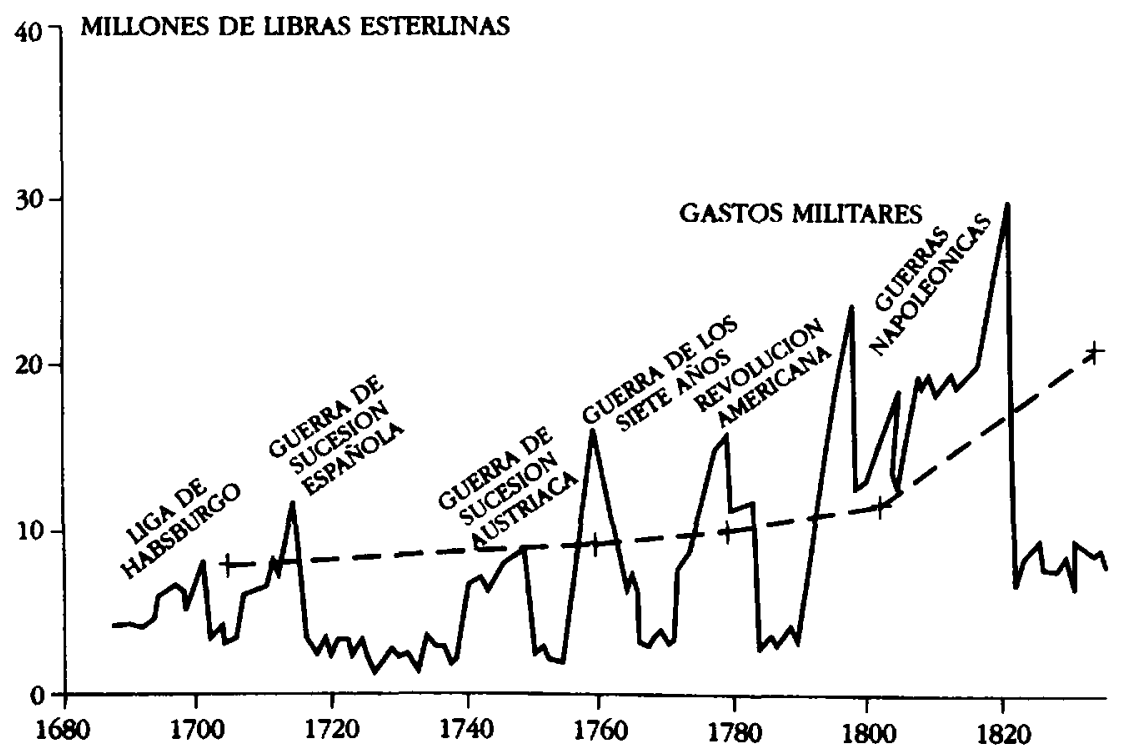

62 El mejor intento de analizar el impacto de las Guerras Napoleónicas es el realizado por Mokyr y Savin (1976). En él presta especial atención a la desorganización, además de a la desviación de recurso o usos militares. Véase también Mokyr (1987). 


\section{FIGURA 5}

Inversión, deuda pública y "aborro total" por décadas, 1760-1849

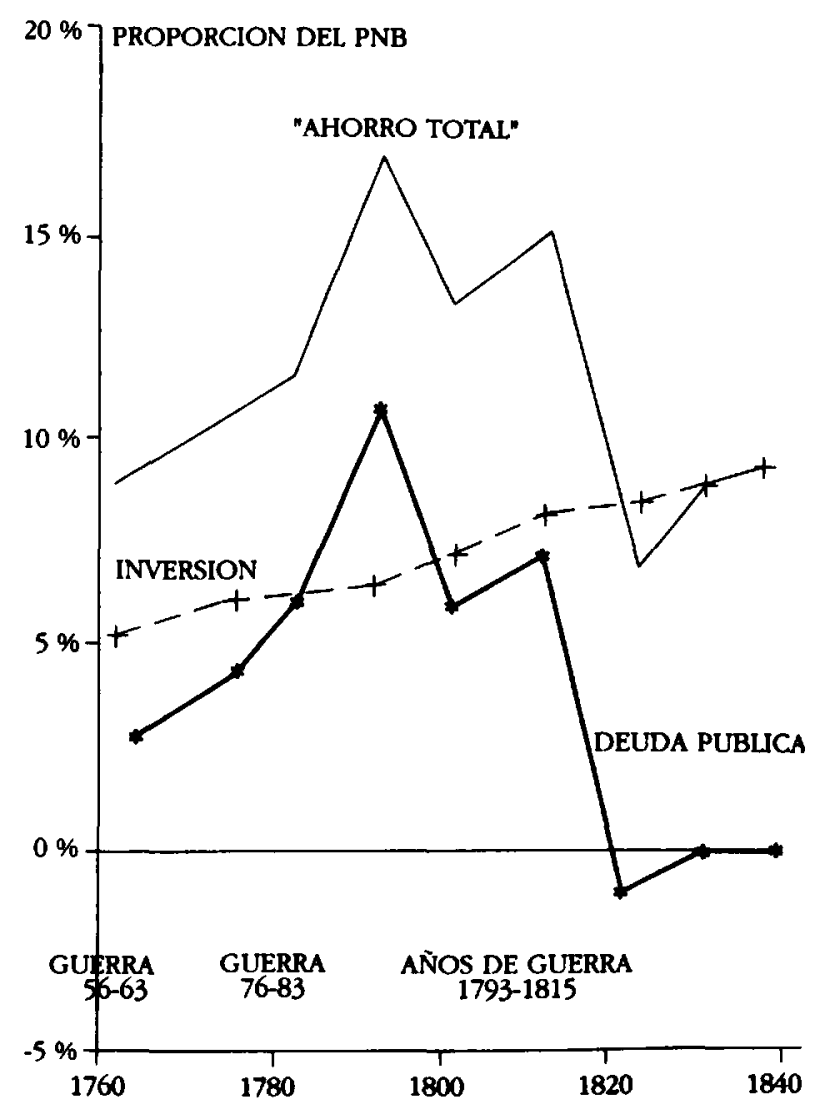

de capacidad previamente no utilizada (III) de la inversión o (IV) del consumo. Los recursos del extranjero y la movilización de recursos infraempleados anteriormente jugaron sólo un pequeño papel. El aumento de los impuestos restó recursos principalmente del consumo. Una gran parte de los gastos de guerra fue financiada por la deuda pública: chasta qué punto esto retrajo la inversión?

En las carteras de los ricos, la emisión de valores públicos competía con las ofertas de bienes inmobiliarios. En el límite, cada libra prestada al gobierno pudo haber desplazado una libra de la inversión privada en potencia. Al contrario que la inversión privada, los gastos de guerra del gobierno no aumenta- 
ban el capital social ni la productividad futura, de modo que el crecimiento se frenaria. Según Williamson 63: *calcular un efecto de expulsión ("crowding out") del uno-por-uno tal vez no sea una inadecuada descripción del comportamiento durante la revolución industrial británica».

Los modelos macroeconómicos de pleno empleo (Modigliani, 1961) inspiraron la hipótesis del efecto expulsión. En estos modelos la producción corriente y el ahorro individual - la voluntad de acumular activos, bien sean de capital real o de deuda pública - son exógenos. La demanda de fondos por parte del gobierno hace subir el tipo de interés real hasta que la cifra de inversión privada se reduce en la misma cantidad que la deuda pública.

El estudio detallado de los años de guerra ha puesto en duda la teoria de que el efecto expulsión de tiempo de guerra frenó fuertemente la inversión. La historia del ahorro y de los tipos de interés no se corresponde bien con las previsiones del modelo del efecto de expulsión. La Figura 5 resume la inversión, la deuda pública y la suma de ambas («ahorros totales») como una parte proporcional de la renta a finales del siglo xviu y principios del xIx. Contrariamente al modelo, los «ahorros totales» no parece que fueron independientes de la actividad de la guerra, sino que aumentaron de forma pronunciada durante ésta, para después volver a descender. La inestabilidad de los «ahorros totales» medidos se debió casi enteramente a la volatilidad de la deuda pública. La formación de capital bruto aumentó con bastante regularidad durante la guerra a pesar de la deuda pública 64.

Los modelos del efecto expulsión se apoyan en que la elevación de los tipos de interés real desalientan la inversión privada; por tanto un análisis del movimiento de los tipos de interés también echa luz sobre el proceso que tuvo lugar en tiempo de guerra. El tipo de interés real es un concepto difícil de precisar. El tipo de interés nominal del mercado representa el intercambio de cantidades monetarias presentes y futuras y sólo suministran datos sobre los tipos de interés real cuando se corrigen con los cambios esperados en el precio del dinero. Por supuesto, los cambios en el precio del dinero preocuparon a los inversores en los años inflacionarios de la guerra, pero no resultaba fácil para los contemporáneos predecir el futuro de los precios. Por un lado, la supresión por parte del Banco de Inglaterra de la convertibilidad de sus billetes en oro en 1797, y por otro, la inflación de tiempos de guerra, hicieron insostenible la confianza en la estabilidad del dinero. Pero los inversores informados probablemente esperaban, con razón, como quedó demostrado, que el fin de las hostilidades traería consigo la restauración de la convertibilidad en oro y el

63 Williamson (1985), p. 117.

64 Feinstin (1988), p. 446. 
descenso de los precios. Diversos modelos para predecir la inflación revelan que los tipos de interés nominal aumentaron menos que la inflación prevista, de modo que los intereses reales bajaron ${ }^{65}$.

La historia de la inversión y de los tipos de interés apunta a que la expulsión de la inversión no fue la principal fuente de recursos para la guerra. ¿De dónde salieron, pues, los recursos para hacer la guerra? El mecanismo más probable parece ser un «impuesto inflacionario ${ }^{66}$. Sirviéndose de una financiación inflacionaria, el gobierno obtuvo recursos de aquellos -incluidos especialmente los perceptores de salarios- que no fueron capaces de predecir la inflación. Probablemente la inflación también benefició a individuos adinerados y bien situados que adquirieron deuda pública con gran parte de sus ganancias. Desde luego los salarios reales se rezagaron durante los años de guerra. La distribución de la renta muestra una interrupción durante el tiempo de guerra del proceso nivelador que se habia iniciado en el siglo xvil con el aumento de las rentas de los más ricos ${ }^{67}$.

Indudablemente la guerra afectó al comportamiento macroeconómico de Gran Bretaña cuando inició el crecimiento moderno. Las campañas militares y la consecuente financiación al gobierno desviaron recursos de usos que hubieran llevado a un crecimiento más rápido. La magnitud exacta de ese impacto no se conoce bien todavía. En una economia internacional pacífica y organiza. da libremente, Gran Bretaña hubiera crecido con más rapidez, pero hasta las guerras del siglo XviI no nació una economía liberal. La hipótesis de Williamson -de que una terminación de las guerras en 1763 casi hubiera duplicado el ritmo de formación de capital, creando una «frase heroica» de la primera Revolución Industrial que se habría parecido más a los periodos de rápido crecimiento inicial en los demás países- parece exagerada. Hay pocas pruebas de que los préstamos al gobierno tuvieran el efecto de exclusión sobre la inversión privada. La larga evolución del desarrollo moderno estuvo acompañada por el lento aumento gradual de la inversión.

\section{CONCLUSION}

La reciente re-evaluación del camino seguido por Gran Bretaña hacia su predominio económico a mediados del siglo XIX subraya tres importantes características. Primera, los comienzos no se produjeron como una discontinui-

65 Mokyr y Savin (1976), p. 209; Mokyr (1987), pp. 293-305; Heim y Mirowski (1987), Black y Gilmore (1990), Heim y Morwski (1991).

66 Bordo y White (1991).

67 Phelps Brown (1988), figura 11.1, pp. 311, 313. 
dad wheroicaw en el tercer cuarto del siglo xvil, sino como una larga evolución. Segunda, la agricultura británica - probablemente por una mayor separación entre la propiedad, los hombres de empresa y la mano de obradesartolló y adoptó cambios que incrementaron la productividad a gran escala. Dado que la agricultura seguia siendo un gran sector, el aumento de su productividad mejoró de forma considerable el nivel de vida. Además, la agricultura cedió mano de obra a otras actividades. Esto no se hizo sin fricciones, pero si de una forma extremadamente rápida para lo que fue la norma internacional. Tercera, unas cuantas innovaciones clave de excepcional impacto establecieron a las empresas británicas como líderes tecnológicos en la producción de textiles y hierro. Con esta ventaja tecnológica, las firmas británicas llegaron a dominar el comercio internacional de estos productos y el crecimiento de estas industrias convirtió a Gran Bretaña en una economía industrial urbana. La urbanización con base industrial tuvo una gran impacto social, pero el impulso tecnológico sólo abarató una pequeña parte de los bienes consumidos por los británicos y probablemente contribuyó menos que el cambio agricola al crecimiento de la renta per cápita.

La primera entrada de Gran Bretaña en el desarrollo económico moderno ocurrió como culminación de largos procesos históricos. El crecimiento de la agricultura debió mucho a la forma de tenencia de la tierra en el peculiar contexto de la estructura británica de clases. El Estado británico había proporcionado seguridad en un ambiente internacional turbulento, aunque para ello hubiera de pagar un alto precio. Internamente, el Estado había creado, aunque en gran parte de forma fortuita, un armazón institucional que sirvió de base al desarrollo.

Los famosos cambios tecnológicos en la industria que llamamos «Revolución Industrial» fueron parte, pero probablemente una parte muy pequeña, del proceso de crecimiento. La industria moderna surgió primero en Gran Bretaña en parte por el carácter dinámico de su economia. Sin embargo, el carácter industrial y urbano de la Gran Bretaña decimonónica estaba en buena parte basado en su extraordinaria tradición tecnológica de los sectores siderúrgico y algodonero. La característica especialmente industrial y urbana de Gran Bretaña en el siglo xix resultó de unos impulsos tecnológicos excepcionales, reforzados por la guerra que demoró la competencia extranjera. La combinación de impulso tecnológico y de la ayuda que la guerra prestó a su ventaja comparativa fue un acontecimiento poco usual - probablemente en parte «un golpe de suertew en el azaroso proceso de la inventiva ${ }^{68}$ - A la larga, probablemente

68 Crafts (1977). 
Gran Bretaña hubiera sido líder en el desarrollo moderno, pero su particular situación en el siglo XIX como «taller del mundow se basó mucho en especiales -y fortuitos-avances en la tecnología del algodón y del hierro.

La ventaja comparativa en los textiles y el hierro, junto con la rápida movilidad de recursos procedentes de la agricultura, condujo a la rápida industrialización y urbanización. Puesto que la productividad industrial no estuvo sino ligeramente por encima de la productividad agricola, la industrialización y la urbanización, per se, dieron lugar a un incremento pequeño del producto agregado y los salarios reales. La estructura competitiva de la industria británica confirió los beneficios del cambio tecnológico en las nuevas industrias de exportación a los consumidores, muchos de los cuales eran extranjeros. Se obtuvo algún beneficio de la especialización internacional, pero los británicos ganaron poco con las exportaciones que hicieron de su isla el taller del mundo. El desarrollo era mucho más que los famosos sectores de exportación y que la «revolución industrial» que trajeron consigo.

El desarrollo económico moderno se inició en Gran Bretaña como un acontecimiento histórico particular y siguió alli un camino diferente del de otras economías en momentos posteriores. Según trabajos recientes sobre la industrialización de la Europa continental, Gran Bretaña no fue el modelo para el crecimiento inicial que allí se produjo. También estas economias se aceleraron lentamente, no emergiendo de forma repentina bajo la influencia de un sector dominante. Su estructura difería de la británica. Los países que comenzaron a crecer más tarde, con frecuencia lo hicieron más deprisa que Gran Bretaña. Los intentos de comprender la revolución industrial britanica apuntando a una intima correspondencia con la experiencia del Tercer Mundo contemporáneo, la del Japón de principios del siglo xx y la de Estados Unidos en el siglo xxx, resultan especialmente anacrónicos. Tanto las circunstancias históricas como las especiales condiciones de sus economias eran muy distintas a las de la Gran Bretaña del siglo xvin. La forma en que se desarrolló Gran Bretaña estuvo más próxima a la de los demás paises de Europa que de economias más remotas, pero, incluso dentro del contexto europeo, Gran Bretaña fue líder y siguió un camino diferente.

\section{BIBLIOGRAFIA}

AlLEN, Robert C. (1979): aInternational Competitiveness in Iron and Steel, 1850-1913 w. Joumal of Economic History, vol. 39, pp. 911.37.

(1991): aAgriculture during the Industrial Revolution, 1700-1850m, Mimeografia 
de ha Universidad de British Columbia (proyecto de capitulo para R. Floud y D. N. McCloskey, eds., The Economic History of Britain since 1700, 2.' ed.).

BaIROCH, Paul (1982): «International Industrialization Levels from 1750 to 1980w. Journal of European Economic History, vol. 11, pp. 269-334.

- (1989): «European Trade Policy, 1815-1914w, en P. Mathias y S. Pollard, eds.; The Cambridge Economic History of Europe, vol. VIII, Industrial Economies: the Development of Economic and Social Policies. Cambridge: Cambridge University Press, pp. $1-160$.

Black, Robert y Gilmore, Clair (1990): *Crowding Out during Britain's Industrial Revolution*. Joumal of Economic History, vol. 50, pp. 109-32.

Berg, Maxine y Hudson, Pat (1992): «Rehabilitating the Industrial Revolution». Economic History Review, vol. 45.

Bordo Michael D. y Whrte, Eugene N. White (1991): «A Tale of Two Currencies: British and French Finance During the Napoleonic Warsw. Joumal of Economic History, vol. 51, pp. 303-316.

BRENNER, Robert (1976): A Agrarian Class Structure and Economic Development in PreIndustrial Europew. Past and Present, vol. 70, pp. 30-74.

Cannadine, D. (1984): *The Present and the Past in the English Industrial Revolution, 1880-1980m. Past and Present, vol. 103, pp, 131-72.

Charters, J. A. (1985): «The Marketing of Agricultural Produce», en Joan Thirsk, ed., The Agrarian History of England and Wales, vol. V, 1640-1750, II. Agrarian Change. Cambridge: Cambridge University Press, pp. 406-502.

Clark, Gregory (1991): «Labor Productivity and Farm Size in English Agriculture before Mechanization: A Notew. Explorations in Economic History, vol. 28, pp. 248.57.

Cole, W. A. (1981): «Factors in Demand, 1700-1780w, en R. C. Floud y D. N. McCloskey, eds., The Economic History of Britain since 1700, vol. 1. Cambridge: Cambridge University Press, pp. 36-65.

Crafts, N. F. R. (1976): *English Economic Growth in the Eighteenth Century: A Reexamination of Deane and Cole's Estimatsw, Economic History Review, vol. 29, pp. 226-35.

(1977): «Industrial Revolution in Britain and France: Some Thoughts on the Question "Why Was England First?", Economic History Review, vol. 30, pp. 429-41.

- (1982): «Regional Price Variations in England in 1843: An Aspect of the Standard of Living Debatew. Explorations in Economic History, vol. 19, pp. 51.70.

- (1983): «Gross National Product in Europe, 1870-1910: Some New Estimates'». Explonations in Economic History, vol. 20, pp. 387-401.

- (1985): British Economic Growth during the Industrial Revolution. Oxford: Oxford University Press.

- (1987): «British Economic Growth, 1700-1850: Some Difficulties of Interpretation*. Explorations in Economic History, vol. 24, pp. 245-68.

- (1989): «Real Wages, Inequality and Economic Growth in Britain, 1750-1850: A Review of Recent Researchw, en P. Scholliers, ed., Real Wages in Nineteenth and Twentieth Century Europe. Oxford: Berg. pp. 75-95.

y HARLEY, C. K. (1992): «Output Growth and the British Industrial Revolution: A Restatement of the Crafts-Harley Viewn, University of Warwick, Mimeografia.

—; Leybourne, S. J., y Milus, T. C. (1989): *Trends and Cycles in British Industrial Production, 1700-1913w. Joumal of the Royal Statistical Society, vol. 152, pp. 43-60. 
Deane, Phyllis (1955): «The Implications of Early National Income Estimates for the Measurement of Long-Term Economic Growth in the United Kingdom». Economic Development and Cultural Chamge, vol. 4, pp. 3.38.

- (1957): «The Output of the British Woolen Industry». Joumal of Economic History, vol. 17, pp. 207-23.

- y Cole, W. A. (1962): British Economic Growth, 1688-1959. Cambridge: Cambridge University Press.

Elusson, Thomas (1886): The Cotton Trade of Great Britain, nueva edición, 1968, Londres, Frank Cass.

EnGLES, F. (1845): The Condition of the Working Class in England.

FARIEY, Susan (1965/6): «The Nineteenth Century Corn Laws Reconsidered*. Economic History Review, vol. 18, pp. 562-73.

Feinstein, C. H. (1978): «Capital Formation in Great Britain», en P. Mathias y M. M. Postan, eds. Cambridge Economic History of Europe, vol. 7, parte 1. Cambridge: Cambridge University Press, pp. 28-96.

- (1988a): «National Statistics, 1760-1920w, en C. H. Feinstein y S. Pollard, eds. Siudies in Capital Formation in the United Kingdom, 1750-1920. Oxford: Oxford University Press, pp. 259-471.

- (1988b): *The Rise and Fall of the Wiliamson Curvew. Joumal of Economic History, vol. 48, pp. 699.729.

HarLey, C. Knick (1980): *Transportation, the World Wheat Trade and the Kuznets Cycle, 1850-1913w. Explorations in Economic History, vol. 18, pp. 218-50.

- (1982): «British Industrialization before 1841: Evidence of Slower Growth during the Industrial Revolution*. Joumal of Ecomomic History, vol. 42, pp. 267-89.

- (1988): Ocean Freight Rates and Productivity, 1740-1913: The Primacy of Mechanical Invention Reaffirmed». Joumal of Economic History, vol. 48, pp. 851-76.

HARTwELL, R. M. (1971): The Industrial Rewolution and Economic Growth. Londres, Methuen.

Herm, Carol E., y Mrrowsku, Philip (1987): «Interest Rates and Crowding-Out during Britain's Industrial Revolutionw. Joumal of Ecomomic History, vol. 47, pp. $117-40$.

- (1991): «Crowding Out: A Response to Black and Gilmore*. Joumal of Economic History, vol. 51, pp. 701-6.

HoffManN, Walther G. (1955): British Indusion, 1700-1950. Oxford, Blackwell.

Holderness, B. A (1989): «Prices, Productivity, and Output», en G. E. Mingay, ed., The Agrarian History of England and Wales, vol. VI, 1750-1850. Cambridge, Cambridge University Press, pp. 84-189.

HopprT, J. (1990): «Counting the Industrial Revolution*. Economic History Review, vol. 43, pp. 173.93.

Hyde, C. K. (1977): Technological Change and the British Iron Industry, 1700-1870. Princeton, Princeton University Press.

Jackson, R. V. [1987]: «The structure of Pay in Nineteenth-Century Britain». Economic History Review, vol. 40, pp. 561-70.

(1990): \& Government Expenditure and British Economic Growth in the Eighteenth Century: Some Problems of Measurementw, Economic History Review, vol. 43, pp. 217.35.

(1992): «Rates of Industrial Growth During the Industrial Revolution*. Economic History Review, vol. 45, pp. 1-23. 
JONES, Eric L. (1981): Agriculture, 1700-1800w, en R. C. Floud y D. N. McCloskey, eds., The Economic History of Brilain since 1700, vol. 1. Cambridge, Cambridge University Press, pp. 66-86.

LEE, R. D. (1973): «Population in Pre-industrial England: an Econometric Analysis». Quarterly Joumal of Economics, vol. 87, pp. 581-607.

- (1988): *Population Homeostasis and English Demographic History», en R. I. Rotberg y T. K. Rabb, eds., Population and Economy. Cambridge, Cambridge University Press,pp. 75-100.

LINDERT, Peter H. (1980): «English Occupations, 1670-1811». Joumal of Economic History, vol. 40, pp. 685-712.

(1986): «Unequal English Wealth since 1670*. Joumal of Political Economy, vol. 94, pp. 1127-62.

- y Wulamson, Jeffrey G. (1982): «Revising England's Social Tables 1688-1812w. Explorations in Economic History, vol. 19, pp. 385-408.

—_ - (1983a): «Reinterpreting Britain's Social Tables, 1688-1913». Explorations in Economic History,vol. 20, pp. 94-109.

-, - (1983b): «English Workers' Living Standards during the Industrial Revolution: A New Looks. Economic History Review, vol. 36, pp. 1-25.

McCloskey, Donald N. (1981): «The Industrial Revolution: A Surveyw, en R. C. Floud y D. N. McCloskey, eds. The Economic History of Britain since 1700, vol. 1. Cambridge, Cambridge University Press, pp. 103-127.

Maddison, Angus (1982): Phases of Capitalist Development. Oxford, Oxford University Press.

Mitchel, B. R. (1975): Abstract of European Historical Statistics. Londres, Macmillan.

- y Deane, P. (1962): Abstract of European Historical Statistics. Cambridge, Cambridge University Press.

Modigliani, F. (1961): *Long-run Implications of Alternative Fiscal Policies and the Burden of the National Debtw. Economic Joumal vol. 71, pp. 730-55.

MoKYR, Joel (1987): «Has the Industrial Revolution Been Crowded Out? Some Reflections on Crafts and Williamsonm. Explorations in Econom History, vol. 24, pp. 293. 319.

-, SAvin, N. E. (1976): «Stagflation in Historical Perspective: the Napoleonic Wars Revisitedw, en P. Uselding, ed. Reseanch in Economic History, vol. 1, pp. 198-259.

NoRTH, Douglass C. (1968): «Sources of Productivity Change in Ocean Shipping, 16001850w. Joumal of Political Economy, vol. 76, pp. 953-70.

O'BRIEN, P. K. (1985): Agriculture and the Home Market for English industry, 16601820w. English Historical Review, vol. 38, pp. 773-800.

(1991): «The State and the Economy 1688-1815\%. Mimeografía del Instituto de Investigación Histórica (Proyecto de capitulo para R. Floud y D. N. McCloskey, eds. The Economic History of Britain since 1700, 2." ed.).

$\longrightarrow$, y S. L. Engerman (1981): «Changes in Income and its Distribution during the Industrial Revolution», en R. C. Floud y D. N. McCloskey, eds. The Economic History of Britain since 1700, vol. 1. Cambridge, Cambridge University Press, pp. 164-181.

PhelPS Brown (1988): Egalitarianism and the Generation of Inequality. Oxford, Oxford University Press.

- y Hopkins, S. V. (1956): «Seven Centuries of the Prices of Consumables, Compared with Builders' Wages Rates». Economica, vol. 23, pp. 296-314. 
Pollard, S. (1980): «A New Estimate of British Coal Production, 1750-1850». Economic History Review, vol. 33, pp. 212-35.

Robinson, Sherman (1989): Multisectoral Models», en H. Chenery y T. N. Srinivasan, eds. Handbook of Development Economics, vol. II. Amsterdam, Elsevier Science Publishers B. V., pp. 885-947.

Rosrow, W. W. [1960]: The Stages of Economic Growth: a Non-Communist Manifesto. Cambridge, Cambridge University Press. Hay traducción al castellano, Las etapas del crecimiento económico, F. C. E. (1961).

RUTHERFORD, T. (1988): «General Equilibrium Modelling with MPS/GE». Manuscrito inédito, Departamento de Economia, Universidad de Western Ontario.

Shoven, J. B., y WhalleY, J. (1984): «Applied General Equilibrium Models of Taxation and International Tradew. Joumal of Economic Literature, vol. 22, pp. 1007-1051.

SolTow, L. (1968): «Long-run Changes in British Income Inequalityw. Economic History Review, 21, 17-29.

THIRSK, Joan (1897): Agricultural Regions and Agrarian History in England, 1500-1750. Basingstoke, Macmillan.

TOYNBEE, A. (1884): Lectures on the Industrial Revolution in England.

VAN ZANDEN, J. L. (1991): «The First Green revolution: the Growth of Production and Productivity in European Agriculture, 1870-1914w. Economic History Review, vol. 44, pp. 215-39.

Willamson, Jeffrey G. (1985): Did British Capitalism Breed Inequality? Londres, Allen \& Unwin.

- (1987): «Debating the British Industrial Revolution». Explorations in Economic History, vol. 24, pp. 269-92.

WRIGLEY, E. Anthony (1986): «Urban Growth and Agricultural Change: Encland and the Continent in the Early Modern Period», en R. I. Rotberg y T. K. Rabb, eds. Population and Economy. Cambridge, Cambridge University Press, pp. 124-68.

_ y SCHOFIELD, R. S. (1981): The Population History of England, 1541-1871: A Reconstruction. Cambridge, Cambridge University Press. 